A $\mathrm{C} \in$ Rec. Nat. Prod. 15:5(2021) 330-355

records of natural

products

\title{
Evidence-Based Medicinal Potential and Possible Role of Selaginella in the Prevention of Modern Chronic Diseases:
} Ethnopharmacological and Ethnobotanical Perspective

\author{
Mohd Adnan $\oplus^{1 *}$, Arif Jamal Siddiqui $\oplus^{1}$, Arshad Jamal $\bigodot^{1}$, \\ Walid Sabri Hamadou $\bigodot^{1}$, Amir Mahgoub Awadelkareem $\odot^{2}$, \\ Manojkumar Sachidanandan $\oplus^{3}$ and Mitesh Patel $\oplus^{4}$
}

\author{
${ }^{I}$ Department of Biology, College of Science, University of Ha'il, Ha'il, P O Box 2440, Saudi Arabia \\ ${ }^{2}$ Department of Clinical Nutrition, College of Applied Medial Sciences, University of Hail, Hail PO \\ Box 2440, Saudi Arabia \\ ${ }^{3}$ Department of Oral Radiology, College of Dentistry, University of Hail, Hail, PO Box 2440, Saudi \\ Arabia \\ ${ }^{4}$ Bapalal Vaidya Botanical Research Centre, Department of Biosciences, Veer Narmad South Gujarat \\ University, Surat, Gujarat, India
}

(Received November 26, 2020; Revised January 29, 2021; Accepted January 31, 2021)

\begin{abstract}
Different species of the genus Selaginella are exploited for various ethnomedicinal purposes around the globe; mainly to cure fever, jaundice, hepatic disorders, cardiac diseases, cirrhosis, diarrhea, cholecystitis, sore throat, cough of lungs, promotes blood circulation, removes blood stasis and stops external bleeding after trauma and separation of the umbilical cord. Though, high content of various phytochemicals has been isolated from Selaginella species, flavonoids have been recognized as the most active component in the genus. Crude extract and different bioactive compounds of this plant have revealed various in vitro bioactivities such as, antimicrobial, antiviral, anti-diabetic, anti-mutagenic, anti-inflammatory, anti-nociceptive, anti-spasmodic, anticancer and anti-Alzheimer. However, more studies into the pharmacological activities are needed, since none of the professed bioactivity of this plant have ever been fully evaluated. Therefore, this review aims to discuss the evidence-based ethnomedicinal and ethnopharmacological uses, phytochemicals and bioactive potential of Selaginella species. It will provide an updated knowledge for ethnobotanists, ethnopharmacologists and other scientific communities to rethink over the possible usage of Selaginella in medicine. Moreover, further explorations are needed to formulate a novel medicinal product from Selaginella extracts for the improvement of human health, together with toxicity evaluations, necessary to ensure about the safety of these medicinal lycophytes.
\end{abstract}

Keywords: Selaginella; chronic diseases; anti-Alzheimer; anti-diabetic; ethnobotany; phytochemistry. (C) 2021 ACG Publications. All rights reserved

\footnotetext{
* Corresponding author: E-Mail: drmohdadnan@gmail.com ; Phone:00-966-533642004

The article was published by ACG Publications 


\section{Introduction}

The cosmopolitan genus Selaginella possessing many species, utilized conventionally for food, medicine, handicrafts and also as ornaments. The Selaginella plants are usually used to cure many ailments including fever, jaundice, hepatic disorders, cirrhosis, diarrhea, cholecystitis, sore throat, cough of lungs. Furthermore, it promotes blood circulation and helps in removal of blood stasis and controlling external bleeding after injury etc. [1]. They are considered to have the high content of numerous phytochemicals such as, carbohydrates, benzenoids, flavonoids, alkaloids, quinoids, chromones, lignans coumarins, phenylpropanoids, oxygen heterocycle, pigments and steroids. Therefore, crude extract and different bioactive compounds isolated from these plants have been evaluated in-vitro for their antimicrobial, antiviral, anti-diabetic, anti-mutagenic, anti-inflammatory, anti-nociceptive, anti-spasmodic and anticancer activities [2-12]. In this context, the aim behind this review is to spotlight the importance of the Selaginella species in the ethnomedicinal and ethnopharmacological fields, describing the detailed phytochemistry with references and scopes for further inventions in a cyclopedic way against various modern and lifestyle-based chronic diseases such as different types of cancer, hypertension, obesity, type 2 diabetes, etc. As, Selaginella is a rich source of diverse and potent bioactive compounds, it is considered as wonder herb in folk medicine.

\subsection{Overview of Genus Selaginella}

Selaginella belongs to the family Selaginellaceae, which is also acknowledged as a "spike moss". It is the only surviving member of the largest genus of heterosporous fern in the family Selaginellaceae. The genus comprises around 700 to 750 species distributed around the globe. Tropical and subtropical areas have maximum diversity in which plants can grow in various types of soil and climate. Some of the species are also found in extreme climate such as dry desert $(S$. lepidophylla, S. sartorii), cool alpine and tundra/Arctic circle (S. selaginoides, S. rupestris) $[13,14]$. Plants are herbaceous, terrestrial, epilithic or occasionally epiphytic, evergreen or sometimes seasonally green. Rhizome erect, creeping, ascending or scandent. Rhizophores are present at the lower part of rhizome, which bearing roots. Two different sizes of leaves are present on their dichotomous branch which are simple and very small in size $(\sim 10 \mathrm{~mm})$. Stem of the small Selaginella species grows approximately up to $3 \mathrm{~cm}$, whereas, large species stems grows up to $50 \mathrm{~cm}$ to approximately $1 \mathrm{~m}$ long [15]. A diversity of secondary bioactive metabolites such as terpenoids (triterpene, steroid), phenolics (flavonoids, tannins, saponins) and alkaloids have been reported [16]. Among these, biflavonoids are considered as most important which are produced from the dimer of flavone and flavanone structures with 5,7-4'- oxygenated pattern [17-19]. Therefore, Selaginella bears immense value due to the presence of large number of potent phytochemical compounds, ethnobotanics and multi-biological activities with a promising resource of various secondary metabolites.

\subsection{Evidence-Based Ehnobotanical and Ethnomedicinal Uses}

Different species of Selaginella have been used as food, medicine, in handicrafts and also as ornaments since primordial time. As the distribution of Selaginella species is seen worldwide, usage of these plants has been observed in traditional ways by the people around the world for various purposes. The most common use of this plant group is its ethnomedical use due to its healing benefits in different health issues, especially incurring fever, against jaundice, diarrhea, cholecystitis, cirrhosis, dysentery and leukorrhagia, sore throat, cough of lung, silicosis, for hematemesis, hemafecia, epistaxis and curing wound [1], diabetes [7], chronic and acute hepatitis [9], urinary tract infections [6], antimutagenic [10] gastritis [5], skin diseases [4], cancer and cardiovascular problems [11], antiinflammatory [2], cytotoxic, immunostimulant and RNA reverse transcriptase inhibitory agent [8] anti-nociceptive [12] and also anti-spasmodic [3]. Different medicinal uses of Selaginella species are described in the Ayurveda, Charaka Samhita, Shusruta Samhita (ca. 100 AD) and Chinese medicines [20]. In Indian mythology, S. bryopteris is described as 'Sanjeevani booti' - A magical herb. In the Ramayana, poet Tulsidas has given the narration of this wonder herb, 'Sanjeevani' which has the power to heal any malady [21]. In Chinese traditional medicine, medicinal importance of different species of Selaginella are described. Such as, the importance of $S$. doederleinii in the treatment of 
cardiovascular diseases, as a bactericide and in cancers of lung, throat, liver and nose [22]; use of $S$. tamariscina in cancer therapy, traumatic bleeding, gastro-intestinal bleeding, metrorrhagia, rectal prolapsed, hematuria, hemoptysis in pulmonary disease, persistence of post-partum lochia discharge and leucorrhoea [23].

Ethnomedicinal importance of $S$. bryopterisis also reported for its use to cure heat stroke and jaundice. Local native people of 'Songhati' in India uses its paste orally to cure beri-beri, dysentery and for rejuvenating, in combination with cow milk. S. bryopteris also used as remedy for epilepsy and liver problem. In the Madhya Pradesh state of India, "Gond" tribes traditionally used it as strength tonic. They make paste of fresh young leaves along with sugar/honey to treat stomach-ache and urinary tract inflammation in children. In the Chhattisgarh state of India, women of 'Bastar' uses dried powder of this herb as remedy for menstrual irregularities, leucorrhoea and to lessen the labour pain [1].

The Murut people of Sabah (Malaysia) also uses the $S$. plana plant decoction bath to cure fever. In New Guinea, people used to consume young shoots (cooked) of $S$. tamariscina. In Vietnam, whole plant of $S$. tamariscina is used by locals as medication for the treatment of burns, hepatitis, jaundice, and as an concoction for haemorrhoids and various respiratory diseases. In Philippines and Malaysia, S. tamariscina is used to treat cough, rectum prolapse, gastro-intestinal haemorrhage, haemoptysis, haematosuria, gravel and excessive menstrual flow by consuming concentrated decoction of the whole plant. It is also used as a styptic and to cover the wound. In Germany, local people use $S$. tamariscina to treat fragile and brittle finger nails by consuming a 'beauty tea' which is prepared from this plant [23]. For horticultural and trade, these plants are also valuable, as they are used in flower bouquets and for indoor decoration [24].

\section{Phytochemistry of Selaginella}

Immense number of studies have been revealed that Selaginella genus is rich with biflavonoids, steroids, alkaloids, alkaloidal glycosides, secolignans, lignans, neolignans, phenylpropanones and caffeoyl derivatives [12]. Maximum bioactive compounds isolated from various species of Selaginella mostly belongs to the class of flavonoids, alkaloids, lignans, pigments, phenylpropanoids, steroids, benzenoids, quinoids, carbohydrates, coumarins, chromones and oxygen heterocycle [25].

\subsection{Flavonoids}

The phenolic compounds "flavonoids" are found in good amount within the Selaginella in the form of biflavonoids. These secondary metabolites are keen to show potent activity viz., antitumor, anti-malarial, anti-allergic, anti-thrombotic, anti-inflammatory, anti-hypertensive, antibacterial, antioxidant, anti-hepatotoxic, estrogenic and antiviral [26]. They are polyphenolic compounds including flavones, flavonols, flavon-3-ols, flavonones, isoflavones and anthocyanins with low molecular weight. Flavonoids worked as vitamin $\mathrm{C}$ enhancer which eventually functions as antioxidants. They can inhibit enzyme activities like cyclooxygenase, lipoxygenase and prostaglandin synthase. Arrangement of functional groups about the nuclear structure in the flavonoids is directly responsible for its antioxidant activity [26]. Commonly occurred flavonoids in various Selaginella species are listed in Table 1 and chemical structures of majorly can be seen in Figure 1. 
$\underline{\text { Table 1. List of various commonly occurred flavonoids from different Selaginella species }}$

\begin{tabular}{|c|c|c|}
\hline Plant Name & Compound & References \\
\hline S. doederleinii & 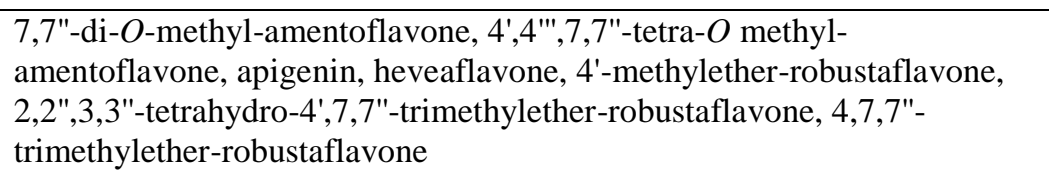 & [27] \\
\hline S. uncinate & $\begin{array}{l}\text { Amentoflavone, 6-(5-carboxyl-2-methoxyphenyl)-apigenin, } \\
\text { hinokiflavone, robustaflavone 7,4',4"'-trimethyl ether, robustaflavone } \\
\text { 4',4"--dimethyl ether, 2,3-dihydroamentoflavone, } \\
\text { 7,4',7"-trimethyl ether, 2,3-dihydroamentoflavone 7,4'-dimethyl ether and } \\
\text { 2",3"-dihydroisocryptomerin 7-methyl ether }\end{array}$ & [28] \\
\hline S. delicatula & $\begin{array}{l}\text { Robustaflavone 4'-methyl ether,robustaflavone 7,4'-dimethyl ether,2",3"- } \\
\text { dihydrorobustaflavone 7,4',-dimethyl ether, 2",3"-dihydrorobustaflavone } \\
7,4^{\prime}, 7 \text { " trimethyl ether, Robustaflavone and amentoflavone }\end{array}$ & [29] \\
\hline S. moellendorffii & $\begin{array}{l}\text { Amentoflavone, robustaflavone, amentoflavone-7,4,7,4- } \\
\text { tetramethylether,4',4'",7,7'"tetra- } O \text { methyl-amentoflavone, 7,4',7' ',4' '- } \\
\text { tetramethylether-amentoflavone, 5-carboxymethyl-4',7-dihydroxyflavone }\end{array}$ & [30] \\
\hline S. bryopteris & $\begin{array}{l}\text { Amentoflavone, 2,3-dihydroamentoflavone, 2",3"-dihydroamentoflavone, } \\
\text { tetrahydroamentoflavone, } \\
\text { 2,3-dihydrohinokiflavone, } 2 ", 3 \text { "-dihydrohinokiflavone, tetrahydro- } \\
\text { hinokiflavone, tetra- } O \text {-methyl-hinokiflavone, lanaroflavone, } \\
\text { sciadopitysin and sequoiaflavone }\end{array}$ & [31] \\
\hline S. willdenowii & $\begin{array}{l}\text { Isocryptomerin, 4',7"-di- } O \text {-methyl-amentoflavone, bilobetin, } 2 ", 3 "- \\
\text { dihydro-isocryptomerin, robustaflavone, } 7 "-O \text {-methyl-robustaflavone }\end{array}$ & [32] \\
\hline S. labordei & $\begin{array}{l}\text { 2",3"-dihydro-3',3"'-biapigenin, 2,3-dihydro-5,5",7,7",4'-pentahydroxy- } \\
\text { 6,6"-dimethyl-(3'-O- 4"')-biflavone,2", 3"dihydroochnaflavone, } \\
\text { amentoflavone and robustaflavone }\end{array}$ & [33] \\
\hline
\end{tabular}

S. tamariscina

Amentoflavone and robustaflavone, 6-(2-hydroxy-5 acetylphenyl)apigenin, 2',8"-biapigenin, cryptomerin $\mathrm{B}$, isocryptomerin, sumaflavone, taiwaniaflavone

S. denticulate Amentoflavone, cryptomerin B, hinokiflavone, isocryptomerin, robustaflavone, sotetsuflavone

\begin{tabular}{ll}
\hline $\begin{array}{l}\text { S. lepidophylla } \\
\text { S. braunii, }\end{array}$ & $\begin{array}{l}\text { Amentoflavone, cryptomerin B, hinokiflavone, isocryptomerin, } \\
\text { robustaflavone, sotetsuflavone, heveaflavone, 2,3-dihydro- } \\
\text { robustaflavone, 2,3-dihydro-5 methylether-robustaflavone }\end{array}$ \\
$\begin{array}{l}\text { S.remotifolia, } \\
\text { S. pulvinata, }\end{array}$ & \\
$\begin{array}{l}\text { S. sinensis, } \\
\text { S. chrysocaulos, }\end{array}$ & \\
S. subalpine, & \\
S. davidii, & Most common flavonoids Ametoflavone and robustaflavone \\
S. kraussiana, & \\
S. pulvinata, & \\
S. rupestris, & \\
S. sanguinolenta, & \\
S. selaginoides, & \\
S. stauntoniana & \\
\end{tabular}


<smiles>O=c1cc(-c2cc(-c3c(O)cc(O)c4c(=O)cc(-c5ccc(O)cc5)oc34)ccc2O)oc2cc(O)cc(O)c12</smiles>

1<smiles>Cc1cc2oc(-c3ccc(Br)cc3)cc(=O)c2c(C)c1-c1cc(-c2cc(=O)c3c(Cl)cc(Cl)cc3o2)ccc1N</smiles>

2<smiles>COc1ccc(-c2cc(=O)c3c(C)cc(OC)c(-c4cc(-c5cc(=O)c6c(C)cc(OC)cc6o5)ccc4C)c3o2)cc1</smiles>

4

7<smiles>O=c1cc(-c2ccc(O)c(-c3c(O)c(O)c(O)c4c(=O)cc(-c5ccc(Cl)cc5)oc34)c2)oc2cc(O)cc(O)c12</smiles>

9<smiles>COc1cc2oc(-c3ccc(O)cc3)cc(=O)c2c(O)c1Oc1ccc(-c2cc(=O)c3c(O)cc(O)cc3o2)cc1</smiles>

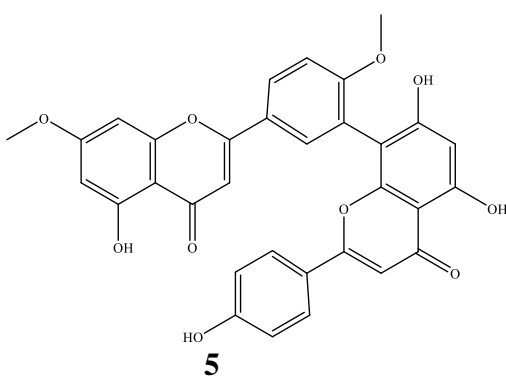<smiles>CCC</smiles>

10<smiles>O=c1cc(-c2ccc(O)cc2)oc2cc(O)cc(O)c12</smiles>

3<smiles>Cc1ccc2c(=O)cc(-c3ccc(Cl)cc3)oc2c1</smiles><smiles>COc1ccc(-c2cc(=O)c3c(O)cc(Cl)cc3o2)cc1-c1c(O)cc(O)c2c(=O)cc(-c3ccc(Cl)cc3)oc12</smiles>

8<smiles></smiles>

(8) Bilobetin (9) Sumaflavone, (10) Taiwaniaflavone

\subsection{Alkaloids}

In the field of medicine, alkaloids are considered as one of the leading group of phytochemicals from which powerful pain killer medications are discovered [37]. 
<smiles>CN(C)CCc1ccc(O)cc1</smiles>

11<smiles>[R][R16]#[R][H]</smiles>

15<smiles>NCCCCNC(=O)/C=C/c1ccc(O)c(O)c1</smiles>

12<smiles>[R][C]OC(=O)/C=C/c1ccc(O)c(O)c1</smiles>

13<smiles>[R][R]#[R][R]</smiles><smiles>C[C@H]1O[C@H](Oc2ccc(CCN(C)C)cc2)[C@H](C)[C@@H](O)[C@@H]1C[C@H]1O[C@H](COC(=O)/C=C/c2ccc(O)cc2)[C@@H](O)[C@H](C)[C@H]1O</smiles>

Figure 2. Major alkaloids identified from Selaginella. (11) Hordenine, (12) Paucine, (13) Paucine3- $\beta$ D-glucopyranoside, (14) Hordenine- $O$ - $\alpha$-rhamnopyranoside, (15) $N$-methyltyramine- $O-\alpha$ rhamnopyranoside, (16) $\mathrm{N}^{1}$-cis- $p$-coumaroylagmatine, (17) Hordenine- $O$-[(6- $O$-cinnamoyl)$O$ - $\beta$-glucopyranosyl]- $\alpha$-rhamnopyranoside, $\quad(18) \quad H o r d e n i n e-O-[(6-O-p$-coumaroyl)- $O-\beta-$ glucopyranosyl]- $\alpha$-rhamnopyranoside

Alkaloids possess multiple pharmacological effects that makes them as an important source of recreational drugs and medications [38]. Alkaloids are known to exhibit anti-inflammatory, analgesic, diuretic and anti-spasmodic activity [39]. Different types of alkaloids were determined with the help of preliminary phytochemical and advanced chromatographic techniques from Selaginella [25]. Different alkaloid compounds such as, hordenine (11), hordenine-(6-O-(4-hydroxy-cinnamoyl)- $\beta$-D-glucosyl) - 
(1,3)- $\alpha$-L-rhamnoside,hordenine-O-(6"-O-trans-cinnamoyl)-4'-O- $\beta$-D-glucopyranosyl- $\alpha$-L-rhamnopyranoside, hordenine- $O-\alpha-\mathrm{L}$ rhamnopyranoside (14), N-methyltyramine-O- $\alpha$-L-rhamnoside, hordenine- $O$-[(6-O-cinnamoyl)-O- $\beta$-glucopyranosyl]- $\alpha$-rhamnopyranoside (17) were detected from the S. Doederleinii [40]. While, in the S. Moellendorffii, selaginellic acid, 5-Hydroxyselaginellic acid, 5hydroxy- $N_{8}, N_{8}$-dimethylpseudophrynaminol, $N$-selaginelloyl- $L$-phenylalanine, $N$-(5-hydroxyselaginelloyl)- $L$-phenylalanineandneoselaginellic acid were detected [30]. Apart from these, $N$-methyltyramine$O$ - $\alpha$-rhamnopyranoside (15), hordenine- $O$-[(6- $O$ - $p$-coumaroyl)- $O$ - $\beta$-glucopyranosyl]- $\alpha$-rhamnopyranoside (18), paucine (12), paucine 3 - $\beta$-D-glucopyranoside (13), $\mathrm{N}^{1}$-cis-p-coumaroylagmatine (16) were also detected from different species of Selaginella [41] (Figure 2).

\subsection{Lignans}

Though lignans are commonly disseminated in higher plants, some of the lignans are also reported to present in the pteridophytes. In this regard, Selaginella is the one in which lignans were detected from some of the species. At ecological level, lignans plays a crucial role in interaction between plant-insect, plant-fungus and plant-plant. Therefore, they exhibit plentiful of biological activities viz., antimicrobial, antitumor, anti-hepatotoxic, antioxidant, anti-tuberculous, antiviral, insecticide and inhibition of certain enzymes [25]. Most important lignans such as, (-)-lirioresinol A (19), (-)-lirioresinol B, (+)-matairesinol (21), (-)-nortracheloside and (+)-wilkstromol (22) were identified from the $S$. doederleinii. Whereas, 5acethyl-dihydro-2-(3',5'-dimethoxy-4'-hydroxyphenyl)-7-methoxybenzofuran, (+) syringaresinol (20), tamariscinoside B (25), tamariscinoside C (27) were detected from the $S$. tamariscina [42]. Two more lignans, sinesiol A and pinoresinoldiglucoside were also detected from the $S$. sinensis [43]. Apart from these, (+) syringaresinol-4,4'-di- $O-\beta-\mathrm{D}-$ glucopyranoside, matairesinol-4,4'-di- $O$ - $\beta$-D-glucopyranoside, styraxlignolide B (23), lariciresinol (24), lariciresinol-4- $O$ - $\beta$-glucopyranoside, $2 R,(3 S)$-dihydro-2-(3',5'-dimethoxy-4'-hydroxyphenyl)-7methoxy-5-acetyl-benzofuran (26), 3,4-trans-3-hydroxymethyl-4-[bis(4-hydroxyphenyl)methyl] butyrolactone (28), 2,3-trans-3,4-trans-2-methoxy-3-hydroxymethyl-4-[bis(4-hydroxyphenyl)methyl] tetrahydrofuran (29) were also reported from different species of Selaginella [41] (Figure 3).

\subsection{Tannins}

Tannins are widely distributed in plants having multiple healing properties in various health issues. They are reported as a potent antibacterial, antiviral, anti-diarrheal, antiparasitic, antihemorrhoidal agents. So many studies have been revealed the presence of tannins in different species of Selaginella such as, S. adoederleinii, S. bryopteris, S. lepidophylla, S. intermedia and S. inaequalifolia [44].

\subsection{Saponins}

Saponins is a group of compounds structurally related to a steroid or triterpenoidaglycone consisting one or more moieties of oligosaccharide. They are well-known for their hemolytic and foaming properties. They are reported as a potent antibacterial and antifungal agent. They can also can form strong insoluble complexes with cholesterol, due to this reason they are considered as useful in the human diet in order to control cholesterol. S. doederleinii is the only species which reported for the presence of saponins [39]. 
<smiles>COc1cc(C2OCC3C(c4cc(OC)c(O)c(OC)c4)OCC23)cc(OC)c1O</smiles>

19<smiles>COc1cc(CC2(O)C(=O)OCC2CC2=CC(OC)C(O)C=C2)ccc1O</smiles>

22

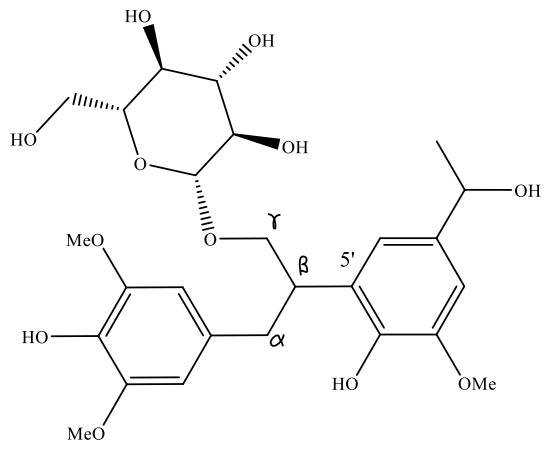

25<smiles>Cc1cc(C(C)C)cc2c1O[C@@H](c1cc(O)c(O[C@H]3O[C@H](CO)[C@@H](C)[C@H](C)[C@H]3O)c([N+](=O)[O-])c1)[C@H]2CO</smiles>

27

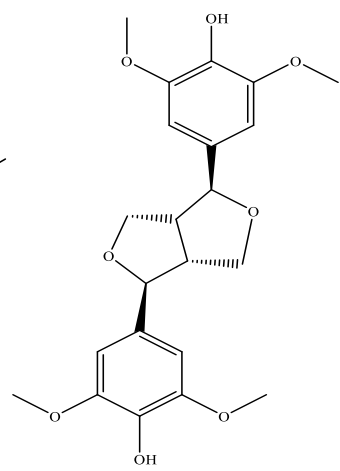

20

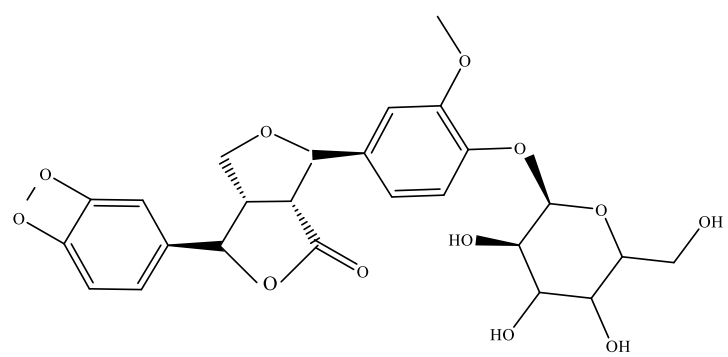

23<smiles>COc1cc(CC2COC(=O)C2Cc2ccc(O)c(OC)c2)ccc1O</smiles>

21<smiles>COc1cc([C@@H]2OC[C@@H](Cc3ccc(O)c(OC)c3)[C@@H]2CO)ccc1C</smiles>

24<smiles>COc1cc([C@@H]2Oc3c(OC)cc(C(C)=O)cc3[C@@H]2CO)cc(OC)c1O</smiles>

26

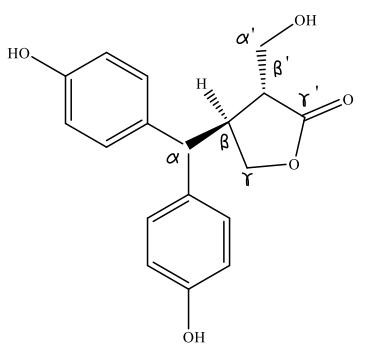

28<smiles>C[C@@H]1OC[C@@](C)(C(c2ccc(O)cc2)c2ccc(O)cc2)[C@@H]1CO</smiles>

29

Figure 3. Major lignans identified from Selaginella. (19) (-)-Lirioresinol A, (20) (+)-Syringaresinol, (21) (+)-Matairesinol, (22)Wikstromol, (23) Styraxlignolide B, (24) (+)-Lariciresinol, (25) Tamariscinoside B (26) (2R,3S)- Dihydro-2-(3,5-dimethoxy-4-hydroxyphenyl)-7-methoxy5-acetyl-benzofuran (27) Tamariscinoside C (28) 3,4-trans-3-hydroxymethyl -4-[bis(4hydroxyphenyl)methyl]butyrolactone, (29) 2,3-trans-3,4-trans-2- methoxy-3hydroxymethyl-4-[bis(4-hydroxyphenyl)methyl]tetrahydrofuran 


\subsection{Pigments}

Biochromes or biological pigments are compounds which are perceived by humans to have colour. They are constituted as bioactive, as they have effect on cell tissue in human body and as a result, they have beneficial health effect on humans. Various type of colors is found in different species of Selaginella such as crimson red, blue chromatic, variegate, silver and yellow gold [45]. Major pigments namely, selaginellin A and B reported from S. tamariscina and selaginellin C, D, E, F, $\mathrm{G}$ and $\mathrm{H}$ are reported from S. pulvinata [46]. Apart from these, selaginellin I, J, K, L, M, N are also reported from other species f Selaginella [41] (Figure 4).

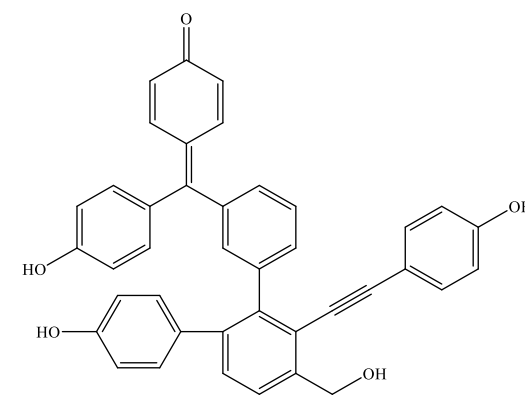

30<smiles>O=C(C=c1cccc(-c2ccc(O)cc2)c1=C(c1ccc(O)cc1)c1ccc(O)cc1)c1ccc(O)cc1</smiles>

33

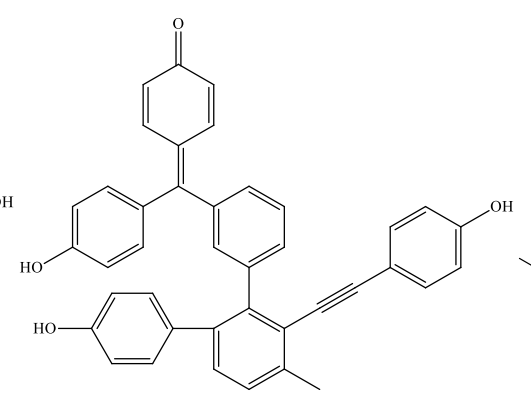

31

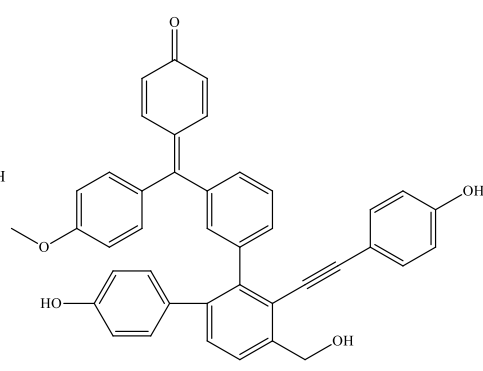

32

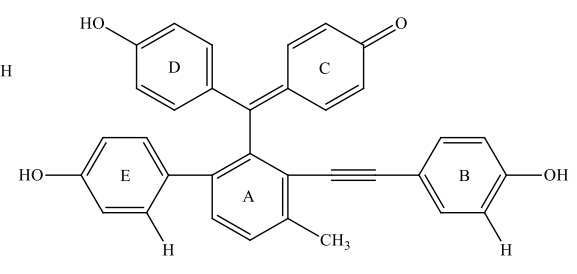

34

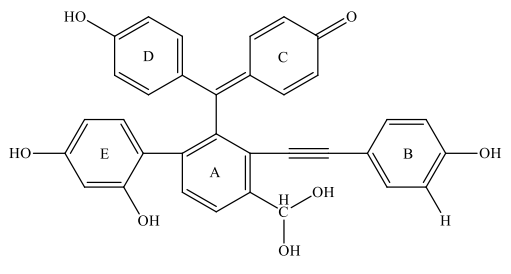

35<smiles>COc1ccc(C(=C2C=CC(=O)C=C2)c2c(-c3ccc(O)cc3)ccc(CO)c2C#Cc2ccc(O)c(C#Cc3c(C(O)O)ccc(-c4ccc(O)cc4C#Cc4ccc(O)c(C=C(c5ccc(O)cc5)c5ccc(O)cc5)c4)c3C(=C3C=CC(=O)C=C3)c3ccc(O)cc3)c2)cc1</smiles>

36

37

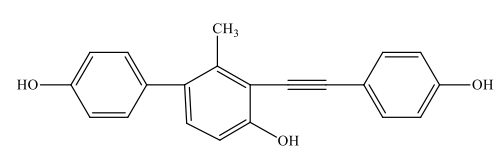

40

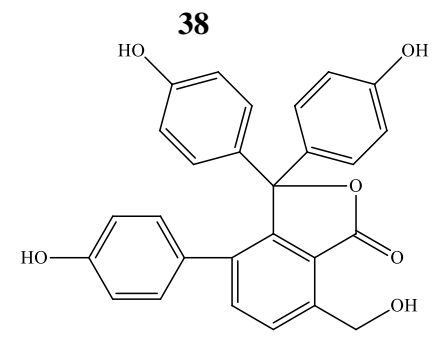

41

Figure 4. Major pigments identified from Selaginella. (30) Selaginellin, (31) Selaginellin A, (32) Selaginellin M, (33) Selaginellin G, (34) Selaginellin B, (35) Selaginellin C, (36) Selaginellin D, (37) Selaginellin E, (38) Selaginellin F, (39) Selaginellin K, (40) Selaginellin L, (41) Selaginellin $\mathrm{H}$ 


\subsection{Terpenoids}

Terpenoids has been reported for its noteworthy pharmacological activities such as antibacterial, anti-malarial, anti-inflammatory, anti-viral, anti-cancer activities and also shows inhibition of cholesterol synthesis. Until now, more than 36000 terpenoid compounds have been identified, due to this reason terpenoids has been considered as the largest class of plant metabolites. According to Almeida et $a l$. , terpenoids can be utilized in storing agricultural products as protective substances due to their insecticidal properties [25]. Literatures described the presence of triterpenoids in the S. tenera and $S$. lepidophylla which are believed to give their anticancer and cytotoxic properties to these species [25].

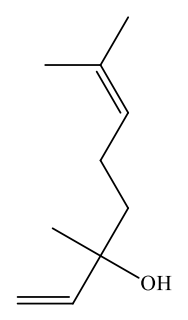

42

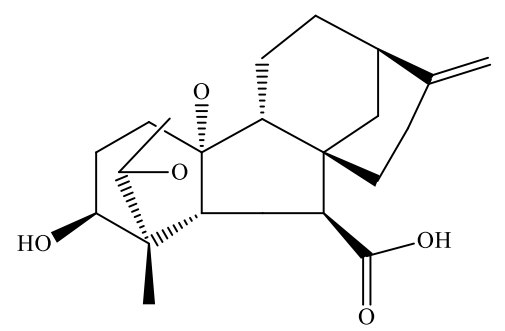

47

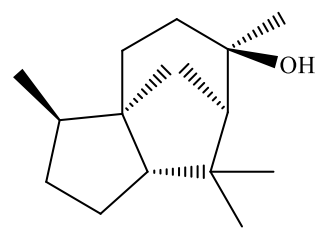

43

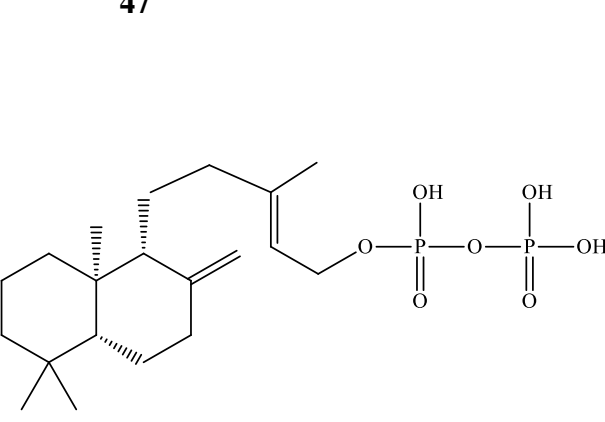

50

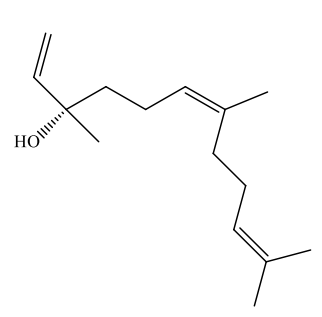

44<smiles>CC(C)C1=CCC2=C(CC[C@H]3C(C)(C)CCC[C@]23C)C1</smiles>

48
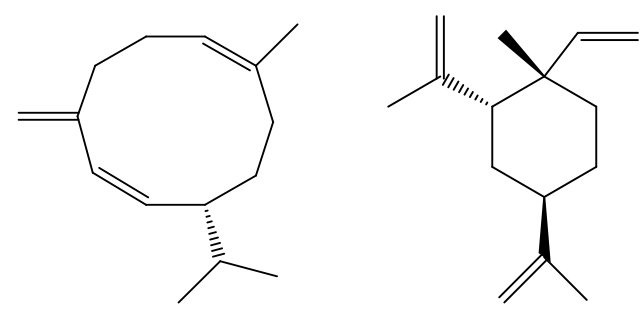

45

45<smiles>CC[C@H]1CC2=CC[C@H]3[C@@H]4CC[C@H]([C@H](C)CC[C@@H](CC)C(C)C)[C@@]4(C)CC[C@H]3[C@@]2(C)CC[C@@H]1C</smiles>

49<smiles>CC1(C)[C@@H](O)CC[C@]2(C)[C@H]1CC[C@]1(C)[C@@H]2C(=O)C=C2[C@@H]3C[C@](C)(C(=O)O)CC[C@]3(C)CC[C@]21C</smiles>

51<smiles>CC[C@H](CC[C@H](C)C1CCC2[C@@H]3CCC4C[C@H](O[C@@H]5O[C@H](CO)[C@@H](O)[C@H](C)[C@H]5O)CC[C@]4(C)[C@H]3CC[C@@]12C)C(C)C</smiles>

Figure 5. Major terpenoids identified from Selaginella (42) Linalool, (43) Cedrol, (44) (+)-(3S) Nerolidol, (45)(+)-Germacrene D, (46) (-)- $\beta$-elemene, (47) Gibberellin A4, (48) Miltiradiene (49) $\beta$-sitosterol (50) Ent-copalyl diphosphate, (51) Glycyrrhetinic acid (52) $\beta$-daucosterin

Different types of terpenoid compounds such as, linalool (42), (4Z,6E)-2,7-dimethyl-8hydroxyocta-4,6-dienoicacid, 8-O- $\beta$-D-glucopyranoside, cedrol (43), (+)-(3S)-nerolidol (44), (+)germacrene $\mathrm{D}$ (45), (-)- $\beta$-elemene (46), $\beta$-sesquiphellandrene, gibberellinA4 (47), gibberellin A24, ent-copalyl diphosphate (50), miltiradiene (48), $\lambda$-7,13e-dien-15-ol, $\beta$-sitosterol (49), $\beta$-daucosterin (52). pulvinatadione, $3 \beta, 16$ '-dihydroxy-5',17 $\beta$-cholestan-21-carboxylic acid, $3 \beta$-acetoxy-16'-hydroxy$5 \alpha, 17 \beta$-cholestan-21-carboxylic acid, $3 \beta$-(3-hydroxybutyroxy)-16 $\alpha$-hydroxy-5 $\alpha$, 17 $\beta$-cholestan-21carboxylic acid, glycyrrhetinic acid (51) and friedelin from different species of Selaginella [41] (Figure 5). 


\subsection{Phenylpropanoids}

Phenylpropanoids are a family of organic compounds having three carbon propene tail and aromatic ring, which are synthesized by plants from phenylalanine and tyrosine. They are reported as a good antioxidant agent in humans. Different phenylpropanoids such as, 3-hydroxy-1-(3,5-dimethoxy4-hydroxyphenyl)-propan-1-one, 3-hydroxy-1-(3-methoxy-4-hydroxyphenyl)-propan-1-one are reported from the $S$. doederleinii [47]. Whereas, caffeic acid, ferulic acid and tamariscine ester A are reported from the S. tamariscina [42].

\subsection{Steroids}

Steroids are group of biologically active compounds having four ring structure. They come with different classes and all different classes have different functional properties. As anabolic steroids can give rise to muscle mass, while anti-inflammatory steroids can decrease aching, swelling and other symptoms of inflammation. They are the universal and regular components of many plants and have been isolated effectively from almost all plants, among which, $\beta$-sitosterolis omnipresent [39]. In Selaginella, steroids are present in different species. Steroid compounds such as 22-

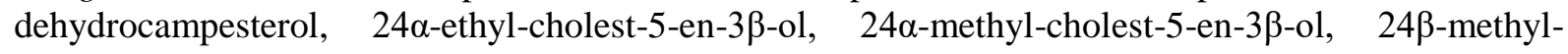

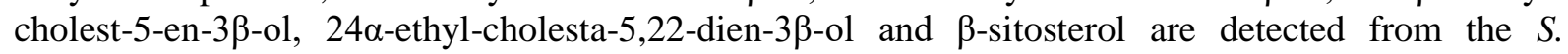
doederleinii. $\beta$-sitosterol is present in S. moellendorffii, S. bryopteris and S. lepidophylla. Whereas, $\beta$ -

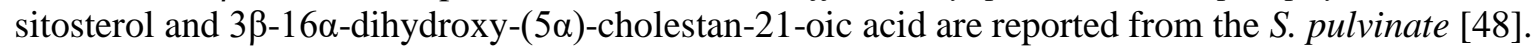

\subsection{Quinoids}

Quinoids are a class of compounds which are derived from quinone. They are mainly known to prevent several diseases like osteoporosis and cardiovascular diseases. Two of the species shows the presence of quinoids viz., S. stauntoniana and S. tamariscina [25].

\subsection{Coumarins}

Coumarins are the group of compounds that have great biological importance with vast structural variety. They are well-known for their antibacterial, anticoagulant, vasodilatory (in coronary vessels) and antitumour activities [49]. They are widely distributed in higher plants but rare in Gymnosperms and lower plants. However, three of the species viz., S. doederleinii, S. moellendorfii, S. tamariscina have been reported for the occurrence of coumarins [25]. Isopimpinellin is reported to present in S. moellendorffii and S. doederleinii. Whereas, umbelliferone and 3-(4-Hydroxyphenyl)-6,7dihydroxy coumarin are reported from the S. tamariscina. Isomers of coumarins known as chromones (Uncinoside A and Uncinoside B) are also reported from few species of Selaginella [50].

\section{Biological Activities of Selaginella}

As listed in previous sections, Selaginella is well-known for its ethnomedicinal properties and chemical diversity, different species of the genus has been studied for its different biological properties, which have assisted in finding out the potent bioactive extracts and constitutes for the development of novel medicinal products and drugs. The biological activities of some species of genus Selaginella are chiefly linked with the findings of anti-diabetic, anti-inflammatory, hepato-protective, antimicrobial, antioxidant, anticancer, anti-nociceptive, anti-spasmodic, anti-mutagenic and antiAlzheimer activities. Therefore, this section elaborates the information on various Selaginella species and their potential medicinal role in different biological activities.

\subsection{Anti-diabetic Activity}

Few researchers reported the anti-diabetic activity of Selaginella species. S. tamariscina is reported to increase the serum levels of insulin, C-peptide and high-density lipoprotein-cholesterol. While, at the same time, it decreases the serum levels of triglyceride, total cholesterol, glucagon, fast 
blood glucose, low density lipoprotein-cholesterol, free fatty acid and glycosylated hemoglobulin A1C. It was also found to improve the oral glucose tolerance test to a certain degree. Additionally, expression of PPAR- $\gamma$ was observed to be improved by S. tamariscina in adipose tissues, which further increases the protein expressions of the IRS-1 in hepatic and skeletal muscle tissues [51]. In another study, aqueous extract of S. bryopteris $(150 \mathrm{mg} / \mathrm{kg} \mathrm{b.w})$ was given to alloxan induced Swiss albino mice up to 26 days for the determination of its anti-diabetic effect. S. bryopteris efficiently reduces the level of glucose and increases the body weight of mice with the release of the shrunken pancreas [52].

\subsection{Anti-inflammatory Activity}

There are many reports on the anti-inflammatory activity of Selaginella species. As reported earlier, two most potent anti-inflammatory biflavonoids namely, hinokiflavone $(\mathrm{H})$ and 7'-O-methyl hinokiflavone $(\mathrm{mH})$ were isolated from the $S$. tamariscina. Their activity was examined through lipopolysaccharide (LPS)-mediated murine macrophages (RAW 264.7) and colon epithelial cells (HT29 ) in which $\mathrm{H}$ and $\mathrm{mH}$ were used to suppress the production tumor-necrosis factor (TNF)- $\alpha$, interleukin (IL)-6, IL-8, and nitric oxide (NO), which are considered as highly active in inflammatory bowel disease (IBD). Also, $\mathrm{H}$ and $\mathrm{mH}$ were found to suppress the expression of cyclooxygenase (COX)-2 and inducible nitric oxide synthase (iNOS) induced by LPS, as well as the activation of extracellular regulated kinases (ERK) and nuclear factor- $\mathrm{KB}(\mathrm{NF}-\mathrm{\kappa B})$ [53].

The ethanolic crude extract of S. tamariscina was evaluated for its anti-inflammatory potential against LPS-induced inflammatory responses. Treatment of ethanolic crude extract on LPS-stimulated RAW 264.7 cells showed significant inhibition in the production of pro-inflammatory cytokines; IL$1 \beta$, IL-6 and inflammatory mediators; $\mathrm{NO}$ and $\mathrm{PGE}_{2}$ in dose-dependent manner. The crude extract was notably suppress the phosphorylations of $\mathrm{I} \kappa \mathrm{B}-\alpha$, MAPKs, NF- $\kappa \mathrm{B}$. Apart from anti-inflammatory, S.tamariscina crude extract also displayed fine free radical scavenging activity and prevents ROS generation with LPS. Expression of HO-1 and Nrf2 were also prompted by the S. tamariscina crude extract. Therefore, it was found that $S$. tamariscina crude extract have anti-inflammatory effects on RAW 264.7 macrophages and considered useful in the preventing or treating inflammatory diseases [54].

The anti-inflammatory effect of $S$. moellendorffii crude extract was evaluated against gouty arthritis. The crude extract was tested on rat model to analyze its effect against accumulation of neutrophil, lipid peroxidation, inflammatory mediators, paw oedema and other histo-pathological alterations in joints, serum urate and kidney injury, which were identified in hyperuricemic mice. With the help of pharmacokinetic studies, itis assumed that the main apigenin glycosides, quantitatively converted into apigenin in the mammalian body. The apigenin is reported to give strong effect on xanthine oxidase. Aqueous extract of $S$. moellendorffii significantly reduces the hyperuricemia in dose-dependent manner, in high dose group, level of blood nitrogen, creatinine and urea decreased significantly in comparison with hyperuricemic control group. High dose of this extract apparently prevents the swelling of paw, reduces the release of TNF- $\alpha$ and IL- $1 \beta$, reduces the gouty joint inflammatory features, lowers the malondialdehyde and myeloperoxidase levels and increases the superoxide dismutase level [55].

One of the studies described that silver (Ag) nanoparticles developed from S. myosurus crude extract could be a possible and promising source for anti-inflammatory drugs. In which, carrageenaninduced and albumin denaturized rat hind paw oedema model were used to measure the antiinflammatory capability of generated nanoparticles, and it was proposed that the Ag nanoparticles can reduce/inhibit agents on the release of acute inflammatory mediators [56].

\subsection{Antimicrobial Activity}

Selaginella is rich in flavonoids and bioflavonoids, which are reported for their powerful activity against microorganisms [25]. The antimicrobial activity of different species of Selaginella have been evaluated against various human pathogenic bacterial and fungal strains, via well or disc diffusion method. One of the studies showed antibacterial and antifungal potential of S. bryopteris against some bacterial and fungal strains viz., E. coli, E. faecalis, C. tropicalis, S. aureus, C. albicans, 
C. krusei and K. pneumonia [57]. S. doederleinii have been reported for its antibacterial potential against different Gram-negative and Gram-positive bacteria [58]. S. equalifolia and S. involvens had also shown potent antimicrobial activity against five poultry pathogens namely, Klebsiella, Salmonella, Staphylococcus, Proteus and Bacillus [59]. S. inaequalifolia had good antagonistic activity against $S$. aureus, $E$. coli and $C$. albicans in a dose dependent manner [60]. S. convoluta had also significant antibacterial potential against B. cereus, E. coli, S. enterica, S. marcescens, $K$. pneumoniae, S. flexneri, E. faecalis and S. aureus [61]. S. tamariscina gave quite potent activity against oral bacterial pathogens such as, P.gingivalis, P. intermedia, S. mutans, S. sobrinus, $S$. gordonii, $F$. nucleatum, $S$. sanguinis, $S$. anginosus, $S . \quad$ ratti, $A$. actinomycetemcomitans, $S$. parasanguinis, S. criceti and S. downei [62].

\subsection{Antioxidant Activity}

In the prevention and treatment of complex diseases such as cancer, diabetes, stroke, atherosclerosis and Alzheimer's, antioxidant-based drug formulations are used [63]. Compounds accountable for such antioxidant activity can be isolated and used for preventing and treating the free radical-related disorders [64]. The antioxidant potential of different species of Selaginella have been evaluated by different methods; from which, most are based on the determination of free radical scavenging activity. Commonly used methods are, ABTS, DPPH, superoxide anion radical scavenging assays and total phenolic content.

Indian Sanjeevani (S. bryopteris) is well known for its protective effect against various stressinduced conditions [65]. The crude extract of $S$. tamariscina have strong antioxidant property as its extract can reduce blood sugar levels and able to act as a lipid peroxide and increases insulin serum [66]. The aqueous extract of $S$. involvens also demonstrated significant antioxidant power to lipid peroxides $\left(\mathrm{EC}_{50}=2 \mu \mathrm{g} / \mathrm{ml}\right)$. This aqueous extract is considered as non-toxic and able to degrade blood cholesterol [67]. The aqueous extract of $S$. involvens, S. delicatula and S. wightii were also displayed in-vitro lipid peroxidation and varying levels of hydroxyl radical scavenging activity. The 50\% inhibition $\left(\mathrm{EC}_{50}\right)$ for in-vitro lipid peroxidation of $S$. wightii, $S$. delicatula and $S$. involvens were $76.6 \pm 4,38.2 \pm 1.2$ and $2.1 \pm 0.1$, respectively. Compare to other two species in hydroxyl radical scavenging activity, S. delicatula was found to be more potent. Moreover, flavonoids obtained from the $S$. doederleinii also possess very strong free radical scavenging activity [68].

\subsection{Hepato-protective Activity}

Hepatic disorders have been considered as an important cause of morbidity and mortality in animals and humans globally. Herbal medicines are known for the treatment and relaxation of various elements including various types of liver disorders. Different species of Selaginella are known for its hepatoprotective properties as they consist large number of bioactive compounds such as amentoflavone, delicaflavone, heveaflavone, ginkgetin, 2',8"-biapigenin, hinokiflavone, taiwaniaflavone, kayaflavone, isocryptomerin, sumaflavone, podocarpusflavone A, robustaflavone and ochnaflavone [69]. S. doederleinii has been reported for its hepatoprotective effects [27]. Different extracts of $S$. labordei are also able to down-regulate the expression of cyclooxygenase-2 gene in the adenocarcinoma CaCo-2 cells of human colon [70].

\subsection{Anti-spasmodic Activity}

Spasmodic condition is basically a muscle cramp which is escorted by a sudden burst of pain. A spasmodic muscle contraction can be caused through many medical conditions like dystonia. Antispasmodic effect of few species of Selaginella has been reported. S. pallescens and S. rupestris are reported for their anti-spasmodic activity due to the presence of flavonoid compound amentoflavone [71]. Apart from these two species, amentoflavone was also identified as an antispasmodic agent in $S$. tamariscina which inhibit the expression of phospholipase C gamma 1 [72]. The crude extract of $S$. pallescens also exhibited the spontaneous inhibition of rat ileum contractions in concentration dependent manner [73]. 


\subsection{Anti-Mutagenic and Anti-Alzheimer Activity}

The reports on anti-mutagenic and anti-Alzheimer activity of Selaginella are few. Antimutagenic efficacy of $S$. doederleinii extract has been reported against benzo [ $\alpha$ ] pyrene [74]. A recent work on anti-Alzheimer activity was carried out with the crude extract of S. doederleinii on Alzheimer disease bearing mice $(\mathrm{AD})$ by Morris water maze test. The extract showed notable and significant development on memory and learning function for $\mathrm{AD}$ mice [75].

\subsection{Antinociceptive Activity}

To further support towards the pharmacological knowledge of Selaginella and to establish the wide uses of different species as a painkiller, anti-nociceptive activity of few species was employed. For the first time, ethanolic crude extract of $S$. convoluta was demonstrated for its anti-nociceptive activity on acetic acid-induced writhing mice. Acetic acid administration intraperitoneally irritates the serous membranes and provokes stereotyped behavior in mice, which further characterized by whole body movement, contractions of abdomen and twisting of dorso-abdominal muscles. S. convoluta ethanolic crude extract administration significantly reduces the acetic acid-induced writhing in mice. This effect of $S$. convoluta crude extract might be due to the inhibition of prostaglandin synthesis, as nociceptive mechanism of abdominal writhing induced by acetic acid, which involves the release of arachidonic acid metabolites via cyclooxygenase (COX), and prostaglandin biosynthesis [12]. Moreover, different flavonoids have been reported as anti-nociceptive and anti-inflammatory agents, due to their potentiality to impede the metabolism of arachidonic acid [76]. Therefore, flavonoids present in the crude extract of S. convoluta might be liable for its anti-nociceptive effect.

\subsection{Cytotoxic and Anticancer Activity}

Currently, cancer is the leading cause of death around the globe. Therefore, finding a cure for this disease is highly needed for human endeavor. Nowadays, priority and importance are being given to researches on complementary and alternative medicine to deal with cancer. Different classes of phytochemicals are ubiquitous in plants and large numbers of phytochemicals have been associated with cytotoxic activities. Selaginella species have different groups of chemical compounds which are well-known to have a wide-range of biological actions and are potential source for finding the novel anticancer drugs. As many of the phytochemical compounds obtained from few of these species possess strong cytotoxic activity against various cancer cell lines. Here, we are describing some examples of reports about the cytotoxic activity of few species of Selaginella.

The cytotoxic activity of ethanolic and aqueous extracts of $S$. doederleinii was evaluated by brine shrimp lethality test and against two cancer cell lines MDAMB231 and HepG2. As a result, 50\% lethal concentration (LC50) in brine shrimp lethality test using ethanolic and aqueous extracts after 24 $\mathrm{h}$ of exposure was found to be $>1000 \mu \mathrm{g} / \mathrm{ml}$. Cancer-origin cell lines MDAMB231 and HepG2 were found to be the most susceptible with the treatments of ethanol (LC50=306 $\mu \mathrm{g} / \mathrm{ml}$ ) and aqueous (LC50 $=329 \mu \mathrm{g} / \mathrm{ml}$ ) extracts of $S$. doederleinii, respectively [77]. The isocryptomerin, derivatives of amentoflavone and robustaflavone from $S$. willdenowii had significant cytotoxic potential against various cancer cells [17]. The crude extract of $S$. tamariscina showed potent anticancer activity against different cancer cell lines. It decreases the metastasis, expression of MMP-2 and 9 and urokinase plasminogen activator in A549 cells and Lewis lung carcinoma [78]; inhibits leukaemia cancer cells HL-60 and U937 [78]; inhibits nucleus antigen cell from stomach epithelium [79]; inhibits gastric cancer cells [79] and induce apoptosis via blockade of fatty acid synthesis in breast cancer [80]. Apart from this, amentoflavone was extracted from the crude extract of S. tamariscina and its anticancer efficacy was screened against five different cancer cells, including HeLa (human cervical carcinoma cells), BEL-7402 (human hepatoma carcinoma cells), MCF-7 (human breast cancer cells), PANC-1 (human pancreatic cancer cells) and HL-60 (human leukemia cells). The extract was efficient in the inhibition of the proliferation of HL-60, MCF-7, HeLa, BEL-7402, PANC-1 and showed remarkable inhibition of HL-60 [81]. 
Table 2. List of various phytochemicals from different Selaginella species and their ethnopharmacological and ethnobotanical uses

Species

\section{S. doederleinii}

S. lepidophylla

\section{Phytochemical/Bioactive Compounds}

\section{Ethnopharmacological and Ethnobotanical References Uses/Against}

\section{Anthocyanins and chalcones}

Isopimpinellin

Hordenine

Hordenine-[6- $O$-(4-hydroxy-cinnamoyl)- $\beta-D$ glucosyl]-(1,3)- $\alpha$ - $L$-rhamnoside Hordenine-O-(6"'O-trans-cinnamoyl)-4'-O- $\beta$ $D$ glucopyranosyl- $\alpha-L$-rhamnopyranoside Hordenine- $O$ - $\alpha$ - $L$-rhamnopyranoside $N$-methyltyramine- $O$ - $\alpha$ - $L$-rhamnoside Phytosterol \& saponins 7,7"-Di-O-methyl-amentoflavone 4',4"',7,7"-Tetra-O-methyl-amentoflavone Apigenin Heveaflavone 4'-methylether robustaflavone 2,2",3,3"-Tetrahydro-4',7,7"-trimethyletherrobustaflavone

4,7,7"-Trimethylether-robustaflavone

(-) - Lirioresinol A

(-) - Lirioresinol B

(+) - Matairesinol

(-) - Nortracheloside

(+) - Wilkstromol

3-Hydroxy-1-(3,5-dimethoxy-4-

hydroxyphenyl)-propan-1-one

3-Hydroxy-1-(3-methoxy-4-hydroxyphenyl)propan-1-one

Cholesterol

22-Dehydrocampesterol

$24 \alpha$-Ethyl-cholest-5-en-3 $\beta$-ol

$24 \alpha$-Methyl-cholest-5-en-3 $\beta$-ol

$24 \beta$-Methyl-cholest-5-en-3 $\beta$-ol

$24 \alpha$-Ethyl-cholesta-5,22-dien-3 $\beta$-ol

$\beta$-Sitosterol

Tannins and cardiacglycosides

3-methylenhydroxy-5-methoxy-2,4-dihydroxy tetrahydrofurane

Robustaflavone

2,3-dihydrorobustaflavone

2,3-dihydrorobustaflavone-5-methyl ether

Heveaflavone
Chorioepithelioma

Choriocarcinoma

Anticancer

Antioxidant

Anti-proliferation

Hepato-protective

Cough

$[22,32,48$,

Sore throat

$77,84-86]$

Bronchitis

Pneumonia

Tonsillitis

Hepatitis

Cholecystitis

Cirrhosis

Ascites

Rheumatoid arthritis

Inhibits contraction of uterus

Cold

Common throat

infections

$[16,36,87]$

Anticancer

Anti-ageing 
Amentoflavone

Robustaflavone

Chromone-8-methyleugenitol

Unicoside A

S. uncinata

Unicoside B

6-(5-Carboxyl-2-methoxyphenyl)-apigenin

Hinokiflavone

Robustaflavone7,4',4"'-trimethyl ether

Robustaflavone4',4'"-dimethyl ether

2,3-dihydroamentoflavone 7,4',7"-trimethyl

ether

Antiviral

Anti-tumor

Anti-anoxic

Antibacterial

Antifungal

[43, 88-91]

Hepatitis

Post-childbirth

2,3-dihydroamentoflavone 7,4'-dimethyl ether 2",3"-dihydroisocryptomerin 7-methyl ether

Robustaflavone

Amentoflavone

2,3-Dihydro-isocryptomerin

Robustaflavone-4'-methyl ether

Robustaflavone 7,4'-dimethyl ether

2",3"-dihydrorobustaflavone 7,4',-dimethyl

ether

2",3"-dihydrorobustaflavone 7,4', 7"-trimethyl

ether

3,5-di-O-caffeoylquinic acid,

Gastric disorders

3,4-di-O-caffeoylquinic acid

Anti-HIV

S. delicatula

4,5-di-O-caffeoylquinic acid

Anti-bradykinin

Anti-oedemic

2",3"-Dihydro-4',7,7"-trimethylether-

robustaflavone

2",3"-Dihydro-4',7,-dimethylether-

robustaflavone

4',7-Dimethylether-robustaflavone

4'-Methylether-robustaflavone

Anti-inflammatory

Anti-leukemic

$[29,47]$

Isochlorogenic acid A

Isochlorogenic acid B

Isochlorogenic acid $\mathrm{C}$

22-Dehydrocampesterol

$24 \alpha$-Ethyl-cholest-5-en-3 $\beta$-ol

$24 \alpha$-Methyl-cholest-5-en-3 $\beta$-ol

$24 \beta$-Methyl-cholest-5-en-3 $\beta$-ol

$24 \alpha$-Ethyl-cholesta-5,22-dien-3 $\beta$-ol

\section{Ginkgetin}

Amentoflavone

Robustaflavone

Isopimpinellin

Selaginellic acid

5-Hydroxyselaginellic acid

S. moellendorffi

5 -hydroxy- $N_{8}, N_{8}$-dimethylpseudophrynaminol

$N$-Selaginelloyl- $L$-phenylalanine

Anti-nociceptive

Antioxidant

Anti-ulcer

$N$-(5-Hydroxyselaginelloyl)- $L$-phenylalanine

Neoselaginellic acid

$N$-5(hydroxyneoselaginelloyl)- $L$-phenylalanine

Amentoflavone-7,4,7,4-tetramethylether

4',4"',7,7"-Tetra-O-methyl-amentoflavone

7,4',7",4"-tetramethylether-amentoflavone

Apigenin-7- $O-\beta$-neohesperidoside

Apigenin-8- $C-\beta-D$ glucopyranoside

Anti-inflammatory

Arthritis

Gonorrhea

Hepatitis

Mastitis

Anticancer

Antioxidant 
6,8-Di- $C$ - $\beta$ - $D$-glucopyranosyl-apigenin

6- $C$ - $\beta-D$-Glucopyranosyl- $8-C-\beta-D$ -

xylopyranosyl-apigenin

6-C- $\beta-D$-Xylopyranosyl-8- $C-\beta-D-$

glucopyranosyl-apigenin

Chrysoeriol

Kayaflavone

Podocarpusflavone A

5-Carboxymethyl-4'-hydroxyflavone-7- $O-\beta-D$ -

glucopyranoside

5-Carboxymethyl-4',7-dihydroxyflavone

[7-Hydroxy-2-(4-hydroxy-phenyl)-4-oxo-4H-

chromen-5-yl]-acetic acid ethyl ester

[7-Hydroxy-2-(4-hydroxy-phenyl)-4-oxo-4H-

chromen-5-yl]-acetic acid butyl ester

Moellenoside A

Moellenoside B

$\beta$-Sitosterol

Amentoflavone

Selaginellin A

Selaginoside

Sinensiol A

S. sinensis

Styraxlignolide D

Neolloydosin

(+)-pinoresinol

4',7"-Di-O-methylamentoflavone

Antiviral

Antimicrobial

Antioxidant

$[43,100]$

7"-O-Methylrobustaflavone

Robustaflavone

Genistin

Ginkgetin

Pinoresinoldiglucoside

S. chrysocaulos

Amentoflavone

Chrysocauloflavones I

Chrysocauloflavones II

Chrysocauloflavones III

3,3'-binaringenin

Amentoflavone

2,3-Dihydroamentoflavone

Tetrahydro-amentoflavone

S. bryopteris

Tetrahydro-hinokiflavone

Tetra- $O$-methyl-hinokiflavone

Lanaroflavone

Sciadopitysin

Sequoiaflavone

Anti-inflammatory

General wounds

Irregular menstruation

Uterine disorders

Antioxidants

Anticancer

Anti-allergic

Antimicrobial

Antifungal

Antibacterial

Antiviral

Antiviral

Anti-tumor

Anti-diabetic

Stomachache

Asthma

\section{Amentoflavone}

Mycose

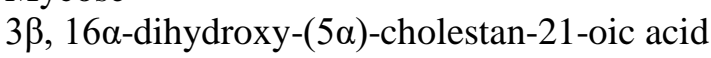

4-Hydroxy-benzoic acid

$\beta$-Sitosterol

Selaginellin C

Selaginellin D 
Selaginellin E

Selaginellin F

Selaginellin $\mathrm{G}$

Selaginellin $\mathrm{H}$

Amentoflavone

Isocryptomerin

4',7"-Di-O-methyl-amentoflavone

Anticancer

Bilobetin

S. willdenowii

Isocryptomerin

2",3"-Dihydro-isocryptomerin

Wound

Fever and Backache

Gastric pains

Urinary tract infections

Robustaflavone

Menstrual pains

7"-O-Methyl-robustaflavone

Skin diseases

Antioxidant

Octaethyleneglycol monododecyl ether

2',6'-Dihydroxyacetophenone,

bis(trimethylsilyl) ether

Decamethylcyclopentasiloxan

Silane,[[4-[1,2 bis[(trimethylsilyl)oxy]ethyl]-

1,2phenylene]bis(oxy)]bis [trimethyl-

Octadecane, 3-ethyl-5- (2- ethylbutyl)

Oxazepam

Hydroquinone

Cyclodecasiloxane, eicosamethyl-

Chloroacetic acid, dodecyl ester

$\alpha$-D-Glucopyranoside, O- $\alpha$-D-glucopyranosyl-

(1.fwdarw.3)- $\alpha$-D-fructofuranosyl

Cyclooctasiloxane, hexadecamethyl-

1-Hexadecanol

8-Methoxy-1,3,4,5- tetrahydro-2H-1-

benzazepin-2-one

Cyclopentanone, 2-(1-methylheptyl)-

$\alpha$-D-Glucopyranose, 4-O- $\alpha$ -

S. tenera

Dgalactopyranosyl-

2-Propenoic acid, 3-(3 fluorophenyl)-, ethyl ester

Hexadecanoic acid, 1 (hydroxymethyl)-1,2

ethanediyl ester

Androst-4-en-6-one, 3,17-diacetoxy-

Pentadecanoic acid, 13-methyl-, methyl ester

Hexadecanoic acid, 1 (hydroxymethyl)-1,2

ethanediyl ester

8-Octadecenoic acid, methyl ester

Heptadecanoic acid, 14-methyl-, methyl ester,

1-Propyl-3,6 diazahomoadamantan-9-ol

8-Ethoxy-4,5-dihydro-1-[(4-

isopropylphenyl)imino] -4,4-dimethyl-1H-

[1,2]dithiolo[3,4-c]quinoline

$2,2,8,8,12,13,17,18$ Octamethyl-2,3,7,8,22,24-

Antibacterial

Antioxidant

Anti-osteoporotic

Prostate disorders

Bone diseases

Antifungal

Anti-neoplastic

Antiviral

Phobic disorders

treatment

Anticancer

Anti-pruritic

Anti-inflammatory

Anti-emphysemic

Platelet aggregation

stimulant

Wound healing

Anti-eczematic

Anti-diabetic

Anti-anginal

Anti-ulcerative

Cardiotonic

Kidney function

stimulant,

Ovulation inhibitor

Dementia treatment

Anti-anginal

Hepato-protectant

Anti-protozoal

Anti-neoplastic

hexahydro-porphine-5-carbonitrile

Cholestane, 1-vinyl-1-hydroxy-

1,4,10,13-Tetraoxa-7,16-diazacyclooctadecane,

7,16-bis(1-oxodecyl)-

1,4,10,13-Tetraoxa-7,16-

diazacyclooctadecane,7,16-bis(1-oxodecyl)- 
4-Normethyl-9,19 cyclolanoststan-7-one, 3-

acetoxy-

S. labordei

S. tamariscina
Amentoflavone

Robustaflavone

2",3"-Dihydro-3',3"' biapigenin

2,3-Dihydro-5,5",7,7",4'-pentahydroxy-6,6"dimethyl-[3'-O-4"']-biflavone

2",3"-Dihydroochnaflavone

4'-methylether robustaflavone

Eriodictyol

Amentoflavone

Robustaflavone

Umbelliferone

3-(4-Hydroxyphenyl)-6,7-dihydroxy coumarin

5-Acethyl-dihydro-2-(3',5'-dimethoxy-4'-

hydroxy-phenyl)-7-methoxybenzofuran

Syringaresinol

Tamariscinoside B

Tamariscinoside $\mathrm{C}$

Caffeic acid

Ferulic acid

Tamariscine ester A

Selaginellin A

Selaginellin B

1-Methoxy-3-methylanthraquinone

6-(2-Hydroxy-5-acetylphenyl)-apigenin

2',8"-Biapigenin

Cryptomerin B

Isocryptomerin

Sumaflavone

Taiwaniaflavone

Vanillic acid

Syringic acid

Arbutin
Antiviral

Antitumor

Inhibit xanthine oxidase

$[28,33]$

and lipooxigenase
Antioxidant

Anticancer

Anti-diabetic

Anti-ageing

Traumatic bleeding

Haemoptysis in

pulmonary disease

Gastro-intestinal

bleeding

Metrorrhagia

Haematuria

Rectal prolapse

Leukorrhea

Cough

Prolapse of the rectum

S. braunii

Amentoflavone

3-(4-Hydroxyphenyl)-6,7-dihydroxy coumarin

Antioxidant

Antiviral

Antibacterial

S. remotifolia

Amentoflavone

Antioxidant

Robustaflavone

Anticancer

S. involvens

Amentoflavone

Robustaflavone

9-Octadecenoic acid

(2-phenyl-1,3-dioxolan-4-yl)methyl ester

S. intermedia
Trans4-(Anisylideneamino) cinnamic Acid

Benzoic acid

2,6 bis[(trimethylsilyl)oxy]-, trimethylsilyl ester

Oxazepam ditms

D-Mannopyranose
Antioxidant

Antimicrobial

[67]

Anti-inflammatory

Anticancer

Antifungal

Antiviral

Alopecia treatment

Prostate disorders treatment 


\begin{tabular}{|c|c|c|c|}
\hline & $\begin{array}{l}\text { Hydroquinone } \\
\text { 1-phenylprophyl } \\
\text { Trichloroacetic acid dodecyl ester } \\
\text { 1-(+)-Ascorbic acid 2,6- dihexadecanoate } \\
\text { 8,11-Octadecadienoic acid methyl ester } \\
\text { 9,12,15-Octadecatrienoic acid methyl ester, } \\
\text { (Z,Z,Z)- } \\
\text { 9,12-Octadecadienoic acid (Z,Z)- } \\
\text { Benzofuran, 2,3-dihydro-2- methyl-5-phenyl- } \\
\text { 3Beta,5-epoxy- } \alpha \text {-homo-5betacholest-4-en- } \\
\text { 3alpha-ol } \\
\text { Hexadecanoic acid, 1- (hydroxymethyl)-1,2- } \\
\text { ethanediyl Ester }\end{array}$ & $\begin{array}{l}\text { Antibacterial } \\
\text { Anti-seborrheic } \\
\text { Anti-eczematic } \\
\text { Vaso-protector } \\
\text { Antioxidant } \\
\text { Anti-neoplastic } \\
\text { Anti-hypoxic } \\
\text { Anti-inflammatory } \\
\text { Anti-protozoal }\end{array}$ & $104,105]$ \\
\hline S. denticulata & $\begin{array}{l}\text { Amentoflavone } \\
\text { Cryptomerin B } \\
\text { Hinokiflavone } \\
\text { Isocryptomerin } \\
\text { Robustaflavone } \\
\text { Sotetsuflavone }\end{array}$ & $\begin{array}{l}\text { Antibacterial } \\
\text { Antioxidant } \\
\text { Antiviral } \\
\text { Anticancer }\end{array}$ & {$[29,35]$} \\
\hline S. selaginoides & $\begin{array}{l}\text { Amentoflavone } \\
\text { Hinokiflavone } \\
\text { Robustaflavone }\end{array}$ & $\begin{array}{l}\text { Antioxidant } \\
\text { Antiviral }\end{array}$ & {$[35]$} \\
\hline S. stauntoniana & $\begin{array}{l}\text { Amentoflavone } \\
\text { Chrysophanic acid } \\
\text { Emodin } \\
\text { Physcion }\end{array}$ & $\begin{array}{l}\text { Antioxidant } \\
\text { Antiviral } \\
\text { Anticancer }\end{array}$ & {$[88,106]$} \\
\hline
\end{tabular}

The antimetastatic activity of amentoflavone was also evaluated using B16F-10 melanomainduced experimental lung metastasis in C57BL/6 mice. The treatment of amentoflavone efficiently decreased the formation of tumour nodule accompanied by reducing lung collagen hydroxyproline, hexosamine, and uronic acid levels [82]. The cytotoxic effect and apoptosis induction potential of hexane, methylene chloride, ethyl acetate and butanol extracts of $S$. plana was performed against MCF-7 cells. Different crude extracts of $S$. plana displayed inhibition of MCF-7 cells with $\mathrm{IC}_{50}$ value of $30 \mu \mathrm{g} / \mathrm{mL}, 19 \mu \mathrm{g} / \mathrm{ml}, 24 \mu \mathrm{g} / \mathrm{ml}$ and $2 \mu \mathrm{g} / \mathrm{ml}$, respectively. Butanol crude extract was found as the highest cytotoxic and apoptotic induction against MCF-7 cancer cells [83]. The cytotoxic and apoptosis activity of three different crude extract (ethyl acetate, ethanol and aqueous) of $S$. uncinata, $S$. tamariscina, S. remotifolia, S. delicatula, S. moellendorfii, S. pulvinata and S. labordei were evaluated using Bel-7402, HT-29 and HeLa cells. In results, S. labordei, S. tamariscina and S. uncinata had higher inhibition of Bel-7402 and HeLa cells whereas, S. moellendorfii had moderate inhibition, but $S$. remotifolia and $S$. pulvinata had almost no inhibitory activities. The major bioactive compounds responsible for the inhibition for cancer cells were bioflavonoids, detected in the ethyl acetate extracts. Moreover, the efficacy of all three extracts of all the plants on cell inhibition and apoptosis were not same, they were highly efficient on HeLa cells than HT-29 cells [28]. Table 2 describes the complete list of bioactive compounds isolated from various species of Selaginella including its ethnopharmacological and ethnobotanical uses. 


\section{Conclusion}

The present review represents the results of the ethnomedicinal, phytochemistry and biological activities on Selaginella species which have been carried out so far. Apart from 700 to 750 species distributed around the globe, few are reported as medicinally useful and very few of them are subjected to research on the phytochemistry and their biological aspects. The information gathered from the available literature, turn evident that the species of the genus Selaginella have pronounced pharmacological prospects. Though these species are merely evaluated, many of the species are still not explored for their pharmacology and phytochemistry. Therefore, there is a gap in the knowledge exists. Hence, more comprehensive studies into the pharmacological activities are needed. It was observed from the available literature, that many of the pharmacological explorations were not corresponded with the traditional uses of the plants. It is noticeable to spotlight that majority of cited traditional claims; for example, in the treatment of cardiovascular diseases were not evaluated pharmacologically. Majority of the studies related to the traditional uses that are further studied or advanced is about the antimicrobial, antiviral and anticancer activities. Moreover, large number of the studies were carried out with organic extracts. Therefore, for the proper validation of the uses of these plants, evaluation should be repeated with decoctions, infusions and aqueous extract, which is the form utilized by the tribal community. Additional research must also be needed with the use of latest technologies for the extraction and purification of the phytochemical compounds in the requisite quantity for in-depth evaluation of the pharmacological activities with their mode of action. Lastly, detailed studies concerning the toxicity are also essential to make sure about the safety of these medicinal lycophytes.

\section{Acknowledgments}

This research has been funded by Scientific Research Deanship at University of Ha'il-Saudi Arabia through project number RG-191194.

\section{ORCID}

Mohd Adnan: 0000-0002-7080-6822

Arif Jamal Siddiqui: 0000-0002-6236-0920

Arshad Jamal: 0000-0001-8242-1279

Walid Sabri: 0000-0001-5221-2791

Amir Mahgoub: 0000-0001-8530-4940

Manojkumar Sachidanandan: 0000-0002-7702-206X

Mitesh Patel: $\underline{0000-0002-9283-2124}$

\section{References}

[1] S. Singh and R. Singh (2015). A review on endemic Indian resurrecting Herb Selaginella bryopteris (L.) Bak 'Sanjeevani', Int. J. Pharm. Sci. Res. 6, 50-56.

[2] B. H. Han, H. J. Chi, Y. N. Han and K. S. Ryu (1972). Screening on the anti-inflammatory activity of crude drugs, Korean J. Pharmacog. 4, 205-209.

[3] H. Itokawa, S. Mihashi, K. Watanabe, H. Natsumoto and T. Hamanaka (1983). Studies on the constituents of crude drugs having inhibitory activity against contraction of the ileum caused by histamine or barium chloride. Screening test for the activity of commercially available crude drugs and the related plant materials. Shoyakugaku Zasshi 37, 223-228.

[4] C. A. Macfoy and A. M. Sama (1983). Medicinal plants in Pujehun district of Sierra Leone, J. Ethnopharmacol. 8, 215-223.

[5] D. S. Han, S. J. Lee and H. K. Lee (1984). Ethnobotanical survey in Korea. Proceedings of the Fifth Asian Symposium on Medicinal Plants and Spices 5, 125

[6] M. Winkelman (1986). Frequently used medicinal plants in Baja California. Norte J. Ethnopharmacol. 18, $109-131$. 
[7] V. Darias, L. Bravo, R. Rabanal, M. C. Sanchez, L. R. M. Gonzalez and P. A. M. Hernandez (1989). New contribution to the ethnopharmacological study of the Canary Islands, J. Ethnopharmacol. 25, 77 92.

[8] K. Ono, H. Nakane, Z. M. Meng, Y. Ose, Y. Sakai and M. Mizuno (1989). Differential inhibitory effects of various herb extracts on the activities of reverse transcriptase and various deoxyribonucleic acid (DNA) polymerases, Chem. Pharm. Bull. 37, 1810-1812.

[9] C. C. Lin and W. S. Kan (1990). Medicinal plants used for the treatment of hepatitis in Taiwan. Am. J. Chinese. Med. 18, 35-43.

[10] Z. M. Meng, Y. Saki, Y. Ose, T. Sato, H. Nagase, H. Kito, M. Sato, M. Mizuno, K. Ono and H. Nakane (1990). Antimutagenic activity by the medicinal plants in traditional Chinese medicines, Shoyakugaku Zasshi 44, 225-229.

[11] R. C. Lin, A. L. Skaltsounis, E. Sequin, F. Tilleguin and M. Koch (1994). Phenolic constituents of Selaginella doederleinii, Planta. Med. 60, 168-170.

[12] P. G. S. Sá, X. P. Nunes, J. T. Lima, J. A. Siqueira-Filho, A. P. Fontana, J. S. Siqueira, L. J. QuintansJúnior, P. K. F. Damasceno, C. R. C. Branco, A. Branco and J. R. G. S. Almeida (2012). Antinociceptive effect of ethanolic extract of Selaginella convoluta in mice, BMC. Complement. Altern. Med. 12, 187.

[13] R. M. Tryon and A. F. Tryon (1982). Ferns and allied plants with special reference to tropical America. Springer-Verlag, New York, DOI: https://doi.org/10.1007/978-1-4613-8162-4

[14] W. S. Judd, C. S. Campbell, E. A. Kellog and P. F. Stevens (1999). Plant systematics: a phylogenetic approach. Sunderland: Sinauer Associates, https://www.nhbs.com/plant-systematics-book-5

[15] R. Mukhopadhyay (2001). A review of the work on the genus Selaginella P. Beauv, Ind. Fern. J. 18, 144.

[16] T. Chikmawati, A. Setyawan and D. Miftahudin (2008). Phytochemical content of Selaginella plant extracts on the island of Java Indonesia. 8th Seminar and Congress of Indonesian Association of Plant Taxonomy (PTTI). Cibinong Science Center, Bogor-Indonesia, pp. 21-23.

[17] G. L. Silva, H. Chai, M. P. Gupta, N. R. Farnsworth, G. A. Cordell, J. M. Pezzuto, C. W. Beecher and A. D. Kinghorn (1995). Cytotoxic biflavonoids from Selaginella willdenowii, Phytochemistry. 40, 129134.

[18] Y. M. Lin, M. T. Flavin, R. Schure, F. C. Chen, R. Sidwell, D. L. Barnard, J. H. Huffman and E. R. Kern (1999). Antiviral activities of bioflavonoids, Planta. Med. 65, 120-125.

[19] A.G. Mercader and A.B. Pomilio (2012). Biflavonoids: occurence, structural features and bioactivity. Nova Science Publisher, Inc. Hauppauge, New York.

[20] K. Kimura and Y. Noro (1965). Pharmacognostical studies on Chinese drug "Gu-sui-bu". I. consideration on"gu-sui-bu" in old herbals (Pharmacognostical studies on fern drugs XI), Syoy akugaku Zasshi 19, 25-31.

[21] R. Antony and R. Thomas (2011). A mini review on medicinal properties of the resurrecting plant Selaginella bryopteris (Sanjeevani), Int. J. Pharma. Life Sci. 2, 933-939.

[22] L. R. Chao, E. Seguin, F. Tillequin and M. Koch (1987). New alkaloid glycosides from Selaginella doederleinii, J. Nat. Prod. 50, 422-426.

[23] H. Ishikawa (1974). Selaginella tamariscina. Hakkusha Ishikawa Haruhiko, Tokyo, Japan (8th printing; in Japanese). 186 pp.

[24] B. S. Kholia (2008). Selaginella bryopteris (L.) Bak. An endemic fern-ally of India under threat, Ind. Fern. J. 25, 73-78.

[25] J. R. G. Almeida, P. G. S. Sá, L. A. R. Macedo, J. A. Filho, V. R. Oliveira and J. M. B. Filho (2013). Phytochemistry of the genus Selaginella (Selaginellaceae), J. Med. Plant Res. 7, 1858-1868.

[26] J. B. Harbone and C. A. Williams (2000). Advances in flavonoid research since 1992, Phytochemistry 55, 481-504.

[27] M. F. Hu, M. H. Yen, J. W. Liao and K. L. Liu (2004). Hepatoprotective effects of the folk medicines of "Yan-Kan-Tang No.1" and "Yan- Kan-Tang No.2" on Rats, Crop. Environ. Bioinfo. 1, 229-238.

[28] J. Li, X. Lei and K. Chen (2014). Comparison of cytotoxic activities of extracts from Selaginella species, Pharmacogn. Mag. 10, 529-535.

[29] L. C. Lin and C. J. Chou (2000). Three new biflavonoids from Selaginella delicatula, Chin. Pharm. J. 52, 211-218.

[30] D. H. Che and J. G. Yu (1986). Analysis on the chemical constituents of jiangnanjuanbai (Selaginella moellendorffii Hieron). Chung Ts'aoYa. 17, 4.

[31] R. C. Swamy, O. Kunert, W. Schuhly, F. Bucar, D. Ferreira, V. S. Rani, B. R. Kumar and A. V. N. A. Rao (2006). Structurally unique biflavonoids from Selaginella chrysocaulos and Selaginella bryopteris, Chem. Biodivers. 3, 405-413. 
[32] J. Li, D. R. Wan and K. L. Chen (2007). RAPD analysis of 8 medicinal species of Selaginella, Zhong Yao Cai 30, 403-406.

[33] J. C. Xu, X. Q. Liu and K. L. Chen (2009). A new biflavonoid from Selaginella labordei Hieron. ex Christ, Chinese Chem. Lett. 20, 939-941.

[34] J. W. Yang, Y. R. Pokharel, M. R. Kim, E. R. Woo, H. K. Choi and K. W. Kang (2006). Inhibition of inducible nitric oxide synthase by sumaflavone isolated from Selaginella tamariscina, J. Ethnopharmacol. 105, 107-113.

[35] J. A. Lopez-Saez, M. J. Perez-Alonso and A. V. Negueruela (1994). Biflavonoids of Selaginella denticulate growing in Spain, Z. Naturforsch. C. 49, 267-270.

[36] M. I. Aguilar, M. G. Romero, M. I. Chávez, B. King-Díaz and B. Lotina-Hennsen (2008). Biflavonoids isolated from Selaginella lepidophylla inhibit photosynthesis in spinach chloroplasts, J. Agric. Food Chem. 56, 6994-7000.

[37] P. C. Kam and A. Liew (2002). Traditional Chinese herbal medicine and anaesthesia, Anaesthesia 57, 1083-1089.

[38] D. F. Rhoades (1979). Evolution of plant chemical defense against herbivores. In Rosenthal GAD, Janzen H (eds.), Herbivores, their interaction with secondary plant metabolites. Academic Press, New York. pp. 3-54.

[39] T. Chikmawati, A. D. Setyawan and Miftahudin (2012). Phytochemical composition of Selaginella sp. from Java Island Indonesia, Makara J. Sci. 16, 129-133.

[40] N. Y. Lee, H. Y. Min, J. Lee, J. W. Nam, Y. J. Lee, A. R. Han, A. Wiryawan, W. Suprapto, S. K. Lee and E. K. Seo (2008) Identification of a new cytotoxic biflavone from Selaginella doederleinii, Chem. Pharm. Bull. 56, 1360-1361.

[41] J. K. Weng and J. P. Noel (2013). Chemodiversity in Selaginella: a reference system for parallel and convergent metabolic evolution in terrestrial plants, Front. Plant Sci. 4, 1-17.

[42] Y. F. Bi, X. F. Zheng, W. S. Feng and S. P. Shi (2004). Isolation and structural identification of chemical constituents from Selaginella tamariscina (Beauv.) Spring. Yao XueXueBao 39, 41-45.

[43] S. C. Ma, P.P. But, V.C. Ooi, Y. H. He, S. S. Lee, S. F. Lee and R. C. Lin (2001). Antiviral amentoflavone from Selaginella sinensis, Biol. Pharm. Bull. 24, 311-312.

[44] S. Suganya, V. Irudayaraj and M. Johnson (2011). Pharmacognostical studies on an endemic SpikeMoss Selaginella tenera (Hook. \& Grev.) Spring from the Western Ghats, South India, J. Chem. Pharm. Res. 3, 721-731.

[45] M. A. Dahlen (1988). Taxonomy of Selaginella: a study of characters, techniques, and classification in the Hong Kong species, Bot. J. Linn. 98, 277-302.

[46] S. Czeladzinski (2003). Selaginella at the Barbican, Plant Herit. 10, 472-476.

[47] L. C. Lin, Y. C. Kuo and C. J. Chou (2000). Cytotoxic biflavonoids from Selaginella delicatula, J. Nat. Prod. 63, 627-630.

[48] P. L. Chiu, G. W. Patterson and T. A. Salt (1988). Sterol composition of pteridophytes, Phytochemistry 27, 819-822.

[49] A. W. Murray, M. J. Solomon and M. W. Kirschner (1989). The role of cyclin synthesis and degradation in the control of maturation promoting factor activity, Nature 339, 280-286.

[50] X. K. Zheng, S. P. Shi, Y. F. Bi, W. S. Feng, J. F. Wang and J. Z. Niu (2004a). The isolation and identification of a new lignanoside from Selaginella tamariscina (Beauv.) Spring. Yао ХиеХиеBaо 39, 719-721.

[51] X. K. Zheng, L. Zhang, W. W. Wang, Y. Y. Wu, Q. B. Zhang and W. S. Feng (2011). Anti-diabetic activity and potential mechanism of total flavonoids of Selaginella tamariscina (Beauv.) Spring in rats induced by high fat diet and low dose STZ, J. Ethnopharmacol. 137, 662-668.

[52] J. K. Singh, R. Kumari, M. D. Obaidullah and A. M. Jha (2014). Effect of Selaginella bryopteris on diabetic swiss albino mice caused by alloxan, Int. J. Basic Appl. Sci. Res. 1, 22-27.

[53] S. Y. Shim, S. G. Lee and M. Lee (2018). Biflavonoids isolated from Selaginella tamariscina and their anti-inflammatory activities via ERK 1/2 Signaling, Molecules 23, 926.

[54] A. N. Won, S. A. Kim, J. Y. Ahn, J. H. Han, C. H. Kim, J. H. Lee and D. I. Kim (2018). HO-1 induction by Selaginella tamariscina extract inhibits inflammatory response in lipopolysaccharide-stimulated RAW 264.7 macrophages, Evid. Based Complement. Altern. Med. Article ID 7816923.

[55] P. Zhao, K. L. Chen, G. L. Zhang, G. R. Deng and J. Li (2017). Pharmacological basis for use of Selaginella moellendorffii in gouty arthritis: antihyperuricemic, anti-inflammatory, and xanthine oxidase inhibition. Evid. Based Complementary Altern. Med. Article ID 2103254

[56] P. Belle, M. F. Eya'ane, K. Lebogang, E. Laure, Z. C. Bogning, A. Antoinette, E. A. M. Hamza, A. B. Dongmo and M. Malik (2018). Eco-friendly synthesis, characterization, in vitro and in vivo antiinflammatory activity of silver nanoparticle-mediated Selaginella myosurus aqueous extract, Int. J. Nanomed. 13, 8537-8548. 
[57] M. Verma, M. Gangwar, M. Sahai, G. Nath and T. Singh (2015). Antimicrobial activity of phytochemicals isolated from Selaginella bryopteris, Chem. Nat. Com. 51, 341-345.

[58] W. Gang, L. S. Hua, Z. H. Lian, J. Y. Mei, S. M. Mei, Y. L. Jiang and Z. X. Mei (2017). Phytochemical screening, antioxidant, antibacterial and cytotoxic activities of different extracts of Selaginella dederleinii, Bangladesh J. Bot. 46, 1193-1201.

[59] S. Nallaiyan and H. Doraiswamy (2011). Phytochemical activity of leaves of Selaginella involvens and Selaginella inaequalifolia extracts on poultry pathogens, Int. J. Curr. Res. 3, 065-068.

[60] V. Irudayaraj, M. Janaky, M. Johnson and N. Selvan (2010). Preliminary phytochemical and antimicrobial studies on a spike-moss Selaginella inaequalifolia (Hook. \& Grev.) Spring, Asian Pac. J. Trop. Med. 3, 957-960.

[61] L. A. R. Macêdo, R. G. O. Júnior, G. R. Souza, A. P. de Oliveira, E. M. de Lavor, M. G. Silva, A. G. M. Pacheco, I. R.A. de Menezes, H. D. M. Coutinho, C. O. Pessoa, M. P. da Costa and J. R. G. da Silva Almeida (2018). Chemical composition, antioxidant and antibacterial activities and evaluation of cytotoxicity of the fractions obtained from Selaginella convoluta (Arn.) Spring (Selaginellaceae), Biotechnol. Equip. 32, 506-512.

[62] S. Choi, K. Y. Lee, E. J. Jang, S. M. Cha and J. D. Cha (2019). Antimicrobial activity of Selaginella tamariscina extract against oral bacteria, Dent. Oral Craniofac. Res. 5, 1-7.

[63] T. P. A. Devasagayam, J. C. Tilak, K. K. Boloor, K. S. Sane, S. S. Ghaskadbi and R. D. Lele (2004). Free radicals and antioxidants in human health: current status and future prospects, J. Assoc. Physicians India 52, 794-804.

[64] E. J. Middleton, C. Kandaswami and T. C. Theoharides (2000). The effects of plant flavonoids on mammalian cells: implications for inflammation, heart disease and cancer, Pharmacol. Rev. 52, 673751.

[65] N. K. Sah, S. N. P. Singh, S. Sahdev, S. Banerji, V. Jha, Z. Khan and S. E. Hasnain SE (2005). Indian herb 'Sanjeevani' (Selaginella bryopteris) can promote growth and protect against heat shock and apoptotic activities of ultra violet and oxidative stress, J. Biosci. 30, 499-505.

[66] N. Miao, H. Tao, C. Tong, H. Xuan and G. Zhamg (1996). The Selaginellata mariscina (Beauv.) Spring complex in the treatment of experimental diabetes and its effect on blood rheology, China J. Chinese Mat. Med. 21, 493-495.

[67] V. Gayathri, V. V. Asha and A. Subramoniam (2005). Preliminary studies on the immunomodulatory and antioxidant properties of Selaginella species, Ind. J. Pharmacol. 37, 381-385.

[68] S. Li, R. Zhu, M. Zhong, Y. Zhang, K. Huang, X. Zhi and S. Fu (2010). Effects of ultrasonic-assistant extraction parameters on total flavones yield of Selaginella doederleinii and its antioxidant activity, $J$. Med. Plant Res. 4, 1743-1750.

[69] A. D. Setyawan (2011). Natural products from genus Selaginella (Selaginellaceae), Biosci. 3, 44-58.

[70] K. Chen, G. W. Plumb, R. N. Bennett and Y. Bao (2005). Antioxidant activities of extracts from five anti-viral medicinal plants, J. Ethnopharmacol. 96, 201-205.

[71] B. K. Chakravarthy, Y. Y. Rao, S. S. Gambhir and K. D. Gode (1981). Isolation of amentoflavone from Selaginella rupestris and its pharmacological activity on central nervous system, smooth muscles and isolated frog heart preparations, Planta Med. 43, 64-70.

[72] H. S. Lee, W. K. Oh, B. K. Kim, S. C. Ahn, D. O. Kang, D. I. Shin, J. Kim, T. I. Mheen and S. Ahn (1996). Inhibition of phospholipase C gamma 1 activity by amentoflavone isolated from Selaginella tamariscina, Planta Med. 62, 293-96.

[73] A. Rojas, M. Bah, J. I. Rojas, V. Serrano and S. Pacheco (1999). Spasmolytic activity of some plants used by the Otomi Indians of Querétaro (México) for the treatment of gastrointestinal disorders, Phytomedicine 6, 367-371.

[74] H. Lee and J. Y. Lin (1988). Antimutagenic activity of extracts from anticancer drugs in Chinese medicine, Mutat. Res. Genet. Toxicol. 204, 229-234.

[75] H. D. Yin, N. W. Ning, X. Z. Zhen, Z. Lin, P. X. Kang, F. C. Alex, S. C. Dong and S. T. Gui (2017). Multi-target screening and experimental validation of natural products from Selaginella plants against Alzheimer's disease, Front. Pharmacol. 8, 539.

[76] L. A. R. Oliveira-Macêdo, A. G. M. Pacheco, S. R. G. Lima-Saraiva, J. C. Silva, R. G. Oliveira-Júnior, G. R. Souza and V. R. Oliveira (2020). Fractions of Selaginella convoluta (Arn.) Spring (Selaginellaceae) attenuate the nociceptive behavior events in mice, Brazilian J. Biol. 80, 57-65.

[77] J. T. Priscilla, S. Geethaa, S. Sreeramanan and M. T. Ong (2014). Brine shrimp lethality test and antiproliferation test against human cancer-origin cell lines using ethanolic and water extracts of Selaginella doederleinii Hieron, J. Biomed. Pharma. Res. 3, 63-69.

[78] S. F. Yang, S. C. Chu, S. J. Liu, Y. C. Chen, Y. Z. Chang and Y. S. Hsieh (2007). Antimetastatic activities of Selaginella tamariscina (Beauv.) on lung cancer cells in vitro and in vivo, J. Ethanopharmacol. 110, 483-90. 
[79] I. S. Lee, A. Nishikawa, F. Furukawa, K. Kasahara and S. U. Kim (1999). Effects of Selaginella tamariscina on in vitro tumor cell growth, p53 expression, G1 arrest and in vivo gastric cell proliferation, Cancer Lett. 144, 93-99.

[80] J. S. Lee, M. S. Lee, W. K. Oh and J. Y. Sul (2009). Fatty acid synthase inhibition by amentoflavone induces apoptosis and antiproliferation in human breast cancer cells, Biol. Pharm. Bull. 32, 1427-1432.

[81] Y. Jing, G. Zhang, M. Enlong, H. Zhang, J. Guan and J. He (2010). Amentoflavone and the extracts from Selaginella tamariscina and their anticancer activity, Chin. Herb. Med. 5, 226-229.

[82] G. Guruvayoorappan and G. Kuttan (2007). Effect of amentoflavone on the inhibition of pulmonary metastasis induced by B16F-10 melanoma cells in C57BL/6 mice, Integr. Cancer Ther. 6, 185-197.

[82] S. Handayani, A. Hermawan, E. Meiyanto and Z. Udin (2013). Induction of apoptosis on MCF-7 cells by Selaginella fractions, J. Appl. Pharm. Sci. 3, 31-34.

[84] P. Chen, J. Y. Sun, N. G. Xie and Y. G. Shi (1995). Chemical constituents of daeycai (Selaginella doederleinii). Zhong Cao Yao 26, 397-399.

[85] K. Y. Pan, J. L. Lin and J. S. Chen (2001). Severe reversible bone marrow suppression induced by Selaginella doederleinii, Clin. Toxicol. 39, 637-639.

[86] I. R. Lee, J. Y. Song and Y. S. Lee (1992). Cytotoxicity of folkloric medicines in murine and human cancer cells, Kor. J. Pharmacog. 23, 132-136.

[87] S. Perez, R. M. Perez, C. Perez, M. A. Zavala and R. Vargas (1994). Inhibitory activity of 3methylenhydroxy-5-methoxy-2, 4-dihydroxy tetrahydrofurane isolated from Selaginella lepidophylaon smooth muscle of Wistar rat, Pharm. Acta. Hel. 69, 149-152.

[88] L. Y. Ma, F. Wei, S. C. Ma and R. C. Lin (2002). Two new chromone glycosides from Selaginella uncinata, Chin. Chem. Lett. 13, 748-751.

[89] L. Y. Ma, S. C. Ma, F. Wei, R. C. Lin, P. P. H. But and S. F. Lee (2003). Uncinoside A and B, two new antiviral chromone glycosides from Selaginella uncinata, Chem. Pharm. Bull. 51, 1264-1267.

[90] X. K. Zheng, K. K. Li, Y. Z. Wang and W. S. Feng (2008). A new dihydrobenzofuranlignanoside from Selaginella moellendorffii Hieron, Chin. Chem. Lett. 19, 79-81.

[91] T. M. Zhu, K. L. Chen and W. B. Zhou (2008). A new flavones glycoside from Selaginella moellendorffii Hieron. Chinese Chem. Lett. 19, 1456-1458.

[92] J. Kim and E. J. Park (2002). Cytotoxic anticancer candidates from natural resources, Curr. Med. Chem. Anti. Cancer Agents. 2, 485-537.

[93] Y. H. Wang, C. L. Long, F. M. Yang, X. Wang, Q. Y. Sun, H. S. Wang, Y. N. Shi and G. H. Tang (2009). Pyrrolidinoindoline alkaloids from Selaginella moellendorfii, J. Nat. Prod. Res. 72, 1151-1154.

[94] Y. Cao, J. J. Chen, N. H. Tan, L. Oberer, T. Wagner, Y. P. Wu, G. Z. Zeng, H. Yan and Q. Wang (2010). Antimicrobial selaginellin derivatives from Selaginella pulvinata, Bioorg. Med. Chem. Lett. 20, 2456-2460.

[95] Y. Cao, J. J. Chen, N. H. Tan, Y. P. Wu, J. Yang and Q. Wang (2010). Structure determination of selaginellins G and H from Selaginella pulvinate by NMR spectroscopy, Magn. Reson. Chem. 48, 656659.

[96] Y. Cao, N. H. Tan, J. J. Chen, G. Z. Zeng, Y. B. Ma, Y. P. Wu, H. Yan, J. Yang, L. F. Lu and Q. Wang (2010). Bioactive flavones and biflavones from Selaginella moellendorffii Hieron, Fitoterapia 81, 253258.

[97] C. M. Sun, S. L. Yu, J. C. Ou and W. J. Syu (1995). Test of biflavones from Selaginella moellendorffii on the in vitro inhibition of HIV-1 protease, J. Chin. Med. 6, 223-230.

[98] C. M. Sun, W. J. Syu, Y. T. Huang, C. C. Chen and J. C. Ou (1997). Selective cytotoxicity of ginkgetin from Selaginella moellendorfiii J. Nat. Prod. 60, 382-384.

[99] W. S. Feng, K. K. Li and X. K. Zheng (2011). A new norlignanlignanoside from Selaginella moellendorfii Hieron, Acta. Pharmaceut. Sin. B. 1, 36-39.

[100] E. R. Woo, J. Y. Lee, I. J. Cho, S.G. Kim and K. W. Kang (2005). Amentoflavone inhibits the induction of nitric oxide synthase by inhibiting NF-kappa B activation in macrophages, Pharmacol. Res. 51, 539546.

[101] P. Rupa and N. L. Bhavani (2014). Preliminary phytochemical screening of desiccated fronds of Selaginella bryopteris (L.) Baker (Pittakalu), World J. Pharma. Res. 3, 1370-1378.

[102] X. Zheng, D. F. Liao, B. Y. Zhu, Q. H. Tuo and Y. L. Xu (2001). Study on chemical constituents of Selaginella pulvinata, Zhong Cao Yao 32, 17-18.

[103] X. Zheng, J. Du, Y. Xu, B. Zhu and D. Liao (2007). A new steroid from Selaginella pulvinata. Fitoterapia 78, 598-599.

[104] X. K. Zheng, Y. F. Bi, W. S. Feng, J. F. Wang and J. Z. Niu (2004). Study on chemical constituents of Selaginella tamariscina (Beauv.) Spring, Yao XиеХиеВаo 39, 266-268.

[105] D. I. Shin and J. W. Kim (1991). Flavonoid constituents of Selaginella tamariscina, Korean J. Pharmacog. 22, 207-210. 
[106] J. F. Liu, K. P. Xu, D. J. Jiang, F. S. Li, J. Shen, Y. J. Zhou, P. S. Xu, B. Tan and G. S. Tan (2009). A new flavonoid from Selaginella tamariscina, Chinese Chem. Lett. 20, 595-597.

[107] J. F. Liu, K. P. Xu, F. S. Li, J. Shen, C. P. Hu, H. Zou, F. Yang, G. R. Liu, H. L. Xiang, Y. L. Zhou, Y. J. Li and G. S. Tan (2010). A new flavonoid from Selaginella tamariscina (Beauv.) Spring, Chem. Pharm. Bull. 58, 549-551.

[108] X. L. Cheng, S. C. Ma, J. D. Yu, S. Y. Yang, X. Y. Xiao, J. Y. Hu, Y. Lu, P. C. Shaw, P. P. Butt and R. C. Lin (2008). Selaginellin A and B, two novel natural pigments isolated from Selaginella tamariscina, Chem. Pharm. Bull. 56, 982-984.

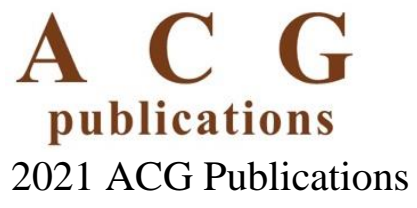

